\title{
The impact of air pollutant and methane emission controls on tropospheric ozone and radiative forcing: CTM calculations for the period 1990-2030
}

\author{
F. Dentener ${ }^{1}$, D. Stevenson ${ }^{3}$, J. Cofala ${ }^{2}$, R. Mechler ${ }^{2}$, M. Amann ${ }^{2}$, P. Bergamaschi ${ }^{1}$, F. Raes ${ }^{1}$, and R. Derwent ${ }^{4}$ \\ ${ }^{1}$ EC-JRC, Institute for Environment and Sustainability, Ispra, Italy \\ ${ }^{2}$ IIASA, International Institute for Applied Systems Analysis, Laxenburg, Austria \\ ${ }^{3}$ University of Edinburgh, School of GeoSciences, Edinburgh, UK \\ ${ }^{4}$ Rdscientific, Newbury, Berkshire, UK
}

Received: 29 November 2004 - Published in Atmos. Chem. Phys. Discuss.: 22 December 2004

Revised: 11 May 2005 - Accepted: 26 May 2005 - Published: 15 July 2005

\begin{abstract}
To explore the relationship between tropospheric ozone and radiative forcing with changing emissions, we compiled two sets of global scenarios for the emissions of the ozone precursors methane $\left(\mathrm{CH}_{4}\right)$, carbon monoxide $(\mathrm{CO})$, non-methane volatile organic compounds (NMVOC) and nitrogen oxides $\left(\mathrm{NO}_{\mathrm{x}}\right)$ up to the year 2030 and implemented them in two global Chemistry Transport Models. The "Current Legislation" (CLE) scenario reflects the current perspectives of individual countries on future economic development and takes the anticipated effects of presently decided emission control legislation in the individual countries into account. In addition, we developed a "Maximum technically Feasible Reduction" (MFR) scenario that outlines the scope for emission reductions offered by full implementation of the presently available emission control technologies, while maintaining the projected levels of anthropogenic activities. Whereas the resulting projections of methane emissions lie within the range suggested by other greenhouse gas projections, the recent pollution control legislation of many Asian countries, requiring introduction of catalytic converters for vehicles, leads to significantly lower growth in emissions of the air pollutants $\mathrm{NO}_{\mathrm{x}}, \mathrm{NMVOC}$ and $\mathrm{CO}$ than was suggested by the widely used and more pessimistic IPCC (Intergovernmental Panel on Climate Change) SRES (Special Report on Emission Scenarios) scenarios (Nakicenovic et al., 2000), which made Business-as-Usual assumptions regarding emission control technology. With the TM3 and STOCHEM models we performed several long-term integrations (19902030) to assess global, hemispheric and regional changes in $\mathrm{CH}_{4}, \mathrm{CO}$, hydroxyl radicals, ozone and the radiative climate

Correspondence to: F.Dentener

(frank.dentener@jrc.it)
\end{abstract}

forcings resulting from these two emission scenarios. Both models reproduce broadly the observed trends in $\mathrm{CO}$, and $\mathrm{CH}_{4}$ concentrations from 1990 to 2002.

For the "current legislation" case, both models indicate an increase of the annual average ozone levels in the Northern Hemisphere by $5 \mathrm{ppbv}$, and up to $15 \mathrm{ppbv}$ over the Indian sub-continent, comparing the 2020s (2020-2030) with the 1990s (1990 2000). The corresponding higher ozone and methane burdens in the atmosphere increase radiative forcing by approximately $0.2 \mathrm{Wm}^{-2}$. Full application of today's emissions control technologies, however, would bring down ozone below the levels experienced in the 1990s and would reduce the radiative forcing of ozone and methane to approximately $-0.1 \mathrm{Wm}^{-2}$. This can be compared to the 0.14 $0.47 \mathrm{Wm}^{-2}$ increase of methane and ozone radiative forcings associated with the SRES scenarios. While methane reductions lead to lower ozone burdens and to less radiative forcing, further reductions of the air pollutants $\mathrm{NO}_{\mathrm{x}}$ and NMVOC result in lower ozone, but at the same time increase the lifetime of methane. Control of methane emissions appears an efficient option to reduce tropospheric ozone as well as radiative forcing.

\section{Introduction}

Methane $\left(\mathrm{CH}_{4}\right)$ and ozone $\left(\mathrm{O}_{3}\right)$ are both key components driving climate change and atmospheric chemistry. Methane concentrations have more than doubled since the pre-industrial era, leading to a radiative forcing of about $0.5 \mathrm{Wm}^{-2}$ (Prather et al., 2001). This growth makes methane therefore, after $\mathrm{CO}_{2}$, the second most important increasing

(C) 2005 Author(s). This work is licensed under a Creative Commons License. 
greenhouse gas in the atmosphere. In large parts of the Northern Hemisphere (NH) photo-oxidation of $\mathrm{CH}_{4}$ and $\mathrm{CO}$ lead to net photochemical production of $\mathrm{O}_{3}$ (Crutzen, 1974), whereas ozone destruction prevails in $\mathrm{NO}_{\mathrm{x}}$ deficient air in parts of the tropics and the Southern Hemisphere (SH). Overall, the combined effect of increasing $\mathrm{CH}_{4}, \mathrm{CO}, \mathrm{NMVOC}$ and $\mathrm{NO}_{\mathrm{x}}$ emissions has resulted in elevated tropospheric $\mathrm{O}_{3}$ levels since pre-industrial times, associated with a net radiative forcing of about $0.35 \mathrm{Wm}^{-2}$ (Ramaswamy et al., 2001).

Besides being a potent greenhouse gas, $\mathrm{O}_{3}$ is also toxic to humans, animals and plants (Buse et al., 2003; WHO, 2003). Ozone levels at a given site are influenced by several factors: (i) background concentrations of ozone and precursor gases, which are determined by large-scale processes, such as stratosphere-troposphere exchange, and global to hemispheric-scale precursor emissions; (ii) regional and local emissions; and (iii) synoptic meteorology, which can favor $\mathrm{O}_{3}$ production, e.g. during a stable high pressure period in summer. Combined, these factors can lead to frequent violations of the contemporary air quality standards for ozone.

Traditionally, the focus of ozone air quality control has been put on the abatement of its local and regional precursor emissions in order to ameliorate short-term episodes of peak ozone concentrations that were considered harmful to human health and vegetation. Recent epidemiological studies reveal damage to human health from ozone not only during such episodes, but also detect significant negative health impacts at much lower concentrations, even at present $\mathrm{NH}$ background levels (WHO, 2003). Based on this finding, the increasing contributions from the intercontinental transport of ozone and ozone precursor gases (Akimoto, 2003), and possibly also increasing measured ozone background concentrations (Vingarzan, 2004), become of immediate concern to air quality managers throughout the world.

A comprehensive model intercomparison exercise involving ten global chemistry-transport models and using projections of the emissions of ozone precursor gases published in the Intergovernmental Panel on Climate Change (IPCC) Special Report on Emission Scenarios (SRES) (Nakicenovic et al., 2000) predicted near-surface ozone to increase by 2030 on average by about five ppbv in much of the NH (Prather et al., 2003) compared to the present modeled background levels of 30-35 ppbv. In the "worst case" (A2p) emission scenario of SRES, background ozone may grow by more than 20 ppbv up to the year 2100 relative to 2000 . Obviously, such increases in background ozone would seriously degrade local air quality throughout the globe and counteract the impacts of costly local and regional emission controls.

However, in the last few years the threat to human health posed by ground-level ozone and particles ("air pollution") has become a universal public concern (Cifuentes et al., 2001; He et al., 2002; Murray et al., 2001), notably also in many cities in developing countries which face rapidly increasing car fleets (Shah et al., 1997; World-Bank, 1997). A number of national and international initiatives have been taken to approach the problem (e.g., the Asian Clean Air Initiative of the World Bank, http://www.cleanairnet.org/ caiasia/). As a consequence, after the year 2000 and after publication of the SRES emission projections report, many of the major developing countries in Asia and Latin America have issued legal regulations requesting advanced emission control techniques for mobile sources. Once fully implemented, these regulations will significantly reduce the growth of air pollution emissions at the regional and global scale, most notably of $\mathrm{NO}_{\mathrm{x}}, \mathrm{NMVOC}$ and $\mathrm{CO}$, compared to earlier projections.

Climate Change policies, on the other hand, focus mostly on $\mathrm{CO}_{2}$ emission reductions, although within the Kyoto protocol (http://unfccc.int/resource/convkp.html) $\mathrm{CH}_{4}$, as well as some other greenhouse gases, are considered. Ozone, however, is not part of the Kyoto protocol. The additional global radiative forcing by ozone and methane between 2100-2000 in the aforementioned SRES A2p scenario was $0.87 \mathrm{Wm}^{-2}$ and $0.59 \mathrm{Wm}^{-2}$, respectively. For comparison: this adds $32 \%$ to the forcing of $\mathrm{CO}_{2}$ alone in the same time period, illustrating the importance of ozone and methane as greenhouse gases.

There is an increased awareness (Hansen et al., 2000) that the most feasible emission reduction strategies are those that take the synergies between air pollution and climate issues into account. For example, Fiore et al. (2002) discuss the strong coupling between methane increases and ozone levels; methane emission reductions could both reduce harmful $\mathrm{O}_{3}$ concentrations and reduce radiative forcing.

In this work we systematically focus on the interaction between $\mathrm{CH}_{4}$ and ozone precursor gases emission controls and their impact on air pollution and climate forcing. Our analysis focuses on the next decades up to 2030, which is of immediate relevance for today's policy decisions.

In Sect. 2 we present a set of global emission projections for the four ozone precursor gases that take into account the recent changes in air quality legislation (CLE). A second set of scenarios describes the maximum feasible emission reductions (MFR) if the full scope of today's emission control technologies would be implemented in the next decades. We compare these scenarios with earlier studies and describe how they were used in the model calculations. Section 3 provides a brief description of the TM3 and STOCHEM models that we used for the simulations. Section 4 compares model results with observations from the period 1990-2002. In Sect. 5, we explore the resulting impacts on global background ozone concentrations, methane lifetime and in Sect. 6 we focus on radiative forcing. In Sect. 7 we discuss the results, and we present the conclusions in Sect. 8 .

\section{Emissions}

In this work we use a set of emissions scenarios developed at the Institute for Applied Systems Analysis (IIASA) using 
the global version of the Regional Air Pollution Information and Simulation (RAINS) model (Amann et al., 1999). The RAINS Current Legislation Scenario (CLE) is based on national expectations of economic growth and present emissions control legislation. While the assumed economic growth (in particular for transport demand) is largely consistent with the assumptions of other global assessments, this study took into account new national legislation on especially mobile sources that has been adopted after the year 2000 in many developing countries in Asia and Latin America. There is some uncertainty about the actual implementation of new legislation in developing countries, especially in the near future, and there maybe a significant lag between increased emissions and actual control measures. However, given the pressure from the strong public concern on local air quality in many developing countries (Cifuentes et al., 2001; He et al., 2002; Murray et al., 2001) and the demonstrated progress in economical and institutional development, it does not seem unreasonable to assume wide-spread compliance with the new regulations by the year 2030 .

The RAINS Maximum Feasible Reduction (MFR) scenario explores the scope for reduced global emissions offered by full application of today's most advanced emission control techniques. Obviously, some of these technical measures are costly, and full application of these measures might have repercussions on economic development. However, in our analysis we focus on the theoretical potential to reduce air pollution and global warming that is offered by today's technological means. At the same time we ignored in our analysis non-technical structural measures that modify energy demand or influence human behavior. Other studies have shown that such measures, if successfully implemented, could lead to significant emission reductions, often at rather low costs (Van Vuuren et al., 2005).

The RAINS scenarios consider agricultural, fossil fuel and biofuel related emissions from $\mathrm{CO}, \mathrm{NO}_{\mathrm{x}}$, and $\mathrm{CH}_{4}$ for the base years 1990, 1995, 2000, 2010, 2020 and 2030. A more extensive description of assumptions made, activity data and emission factors is given in the Appendix. Since RAINS concentrates on the assessment of national emissions, emissions from international shipping and air traffic were not included. Likewise, emissions from large scale biomass burning (deforestation, savannah, agricultural waste burning, and forest fires) and natural emissions are not included in RAINS. For atmospheric calculations these emissions were taken from other studies and added to the national emissions calculated by RAINS, as described in Sect. 2.2.

\subsection{RAINS projections of anthropogenic emissions}

\subsubsection{Nitrogen oxides}

Figure 1a gives an overview of the temporal and regional development of the RAINS CLE and MFR calculated anthropogenic $\mathrm{NO}_{\mathrm{x}}$ emissions. Our calculations indicate a strong
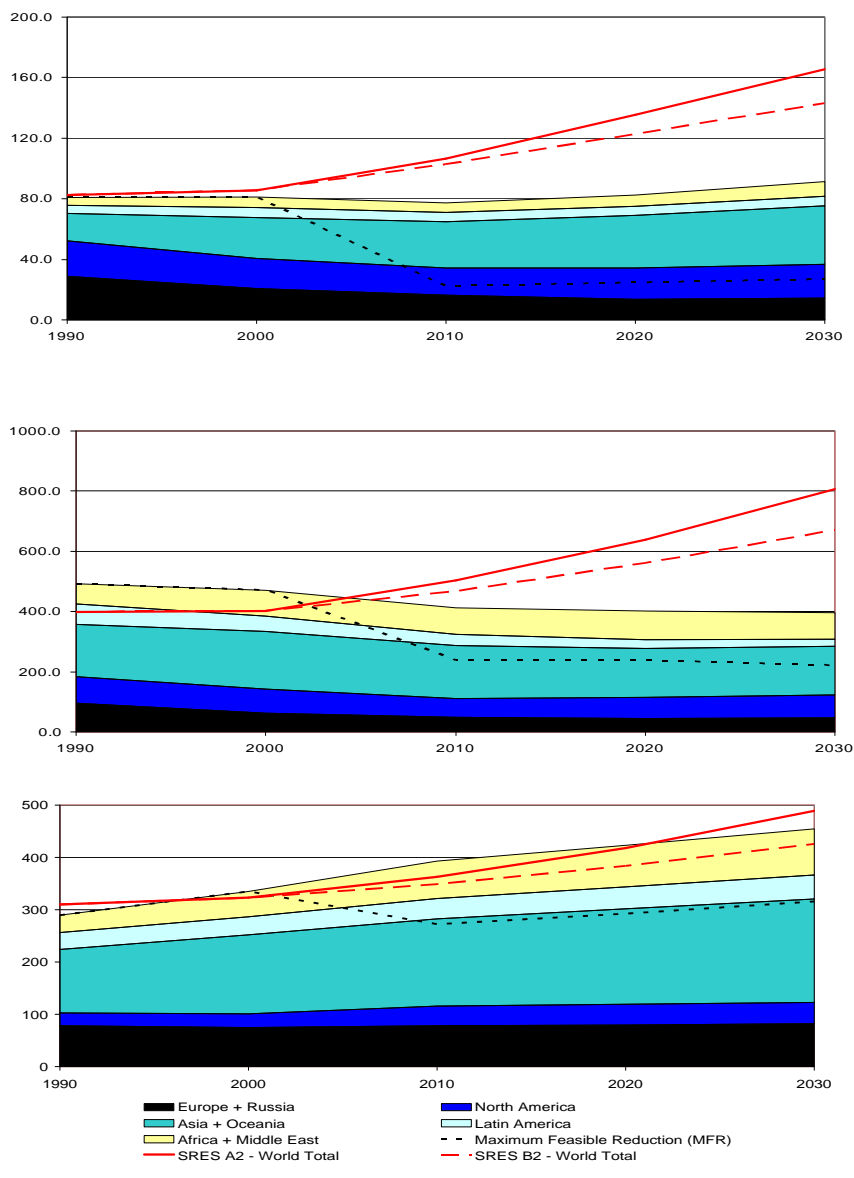

Fig. 1. Projected development of IIASA anthropogenic emissions by SRES world regions upper $\mathrm{NO}_{\mathrm{x}}\left(\mathrm{Tg} \mathrm{NO}_{2} \mathrm{yr}^{-1}\right)$ middle $(\mathrm{CO}$ $\left(\mathrm{Tg} \mathrm{yr}^{-1}\right.$ ) lower $\left.\mathrm{CH}_{4} \mathrm{Tg} \mathrm{yr}^{-1}\right)$. Red lines indicate IPCC SRES scenarios; black dashed line MFR.

decline in Europe and an approximate stabilization in North America of $\mathrm{NO}_{\mathrm{x}}$ emissions, due to present emission control legislation, despite the assumed underlying economic growth (by 2.3 and $1.7 \% \mathrm{yr}^{-1}$, respectively) and the corresponding increase in energy use and transport volumes. For Asia, current national expectations anticipate a growth in transport demand by a factor of 4-5. However, under the assumption of full implementation of the recently decided vehicle pollution control legislation, the growth of $\mathrm{NO}_{\mathrm{x}}$ emissions in Asia will be limited to $35 \%$ in 2030 compared to present. Latin American $\mathrm{NO}_{\mathrm{x}}$ emissions are expected to stabilize due to recently imposed control requirements in the majority of countries in this region. At the global level, this moderate increase in $\mathrm{NO}_{\mathrm{x}}$ emissions from developing countries would be partly offset by the decline in European emissions, resulting in a global anthropogenic $\mathrm{NO}_{\mathrm{x}}$ emissions growth of not more than $13 \%$ in the year 2030 .

Despite the control measures imposed by recent legislation, full application of present best available technology could lead to significant further reductions in the global $\mathrm{NO}_{\mathrm{x}}$ emissions, by approximately $70 \%$ in 2030 for the MFR 


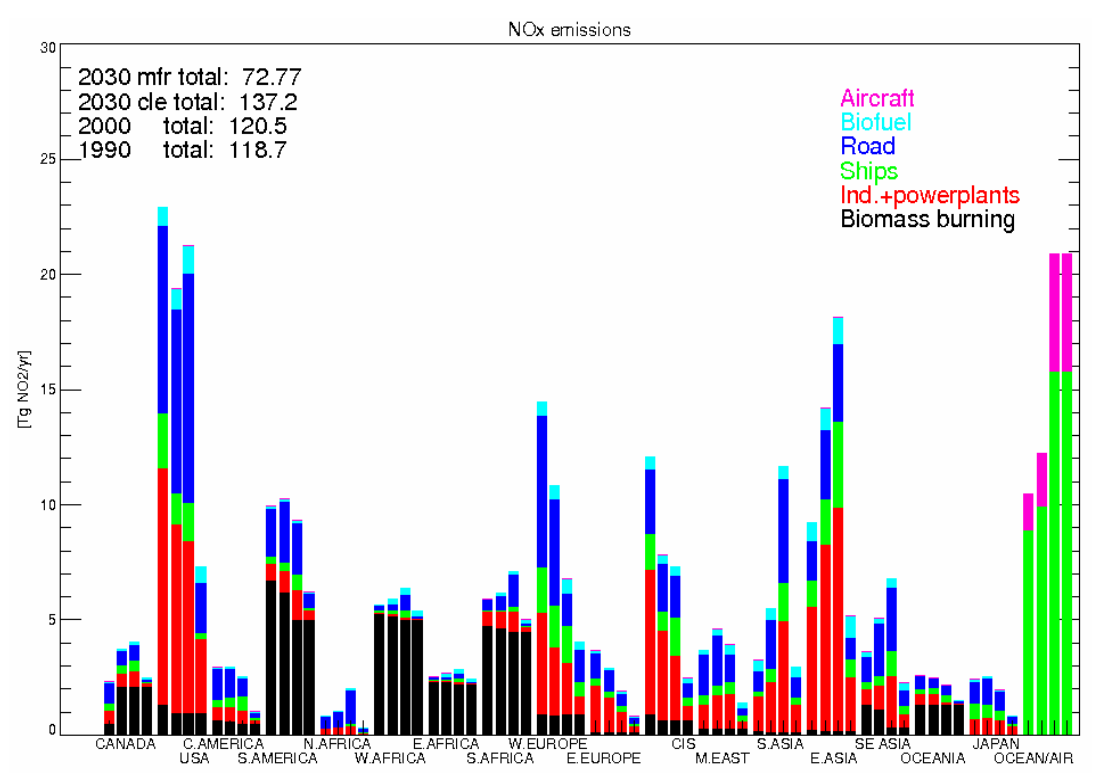

Fig. 2. Regional emissions separated for sources categories in 1990, 2000, 2030-CLE and 2030-MFR for $\mathrm{NO}_{\mathrm{x}}\left[\mathrm{Tg} \mathrm{NO}_{2} \mathrm{yr}^{-1}\right]$. Groups of four bars correspond to 1990, 2000, 2030 CLE, and 2030 MFR, respectively.

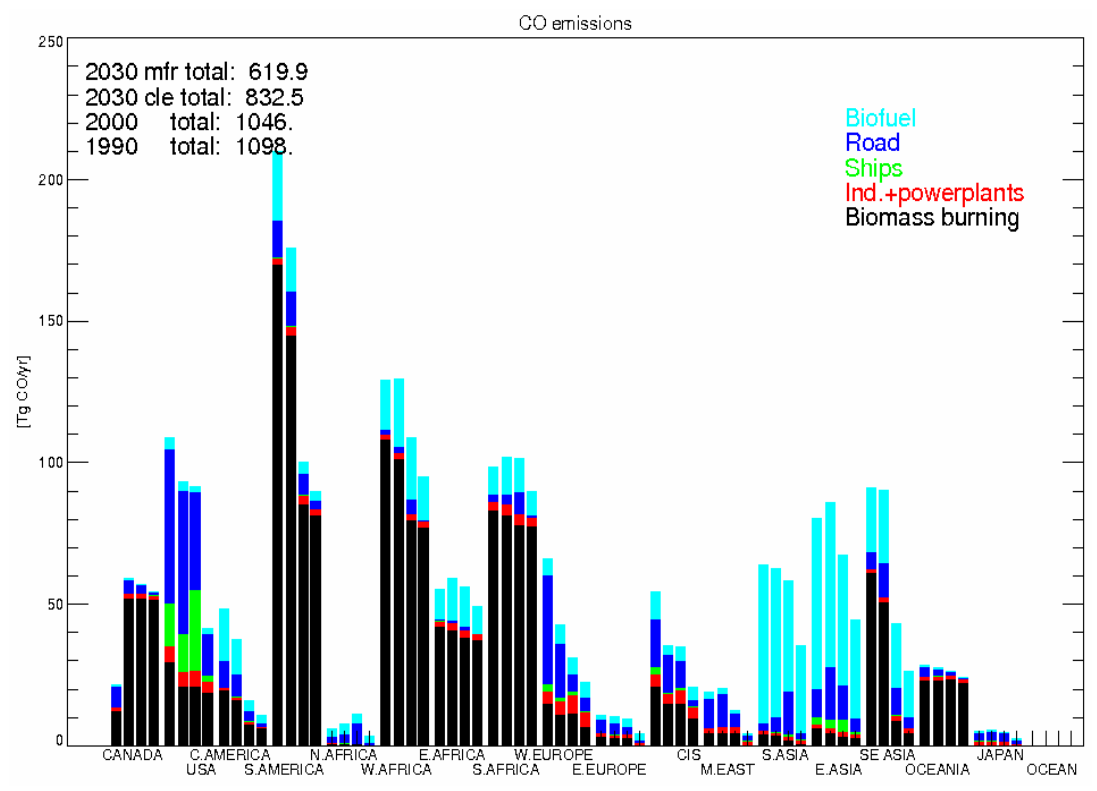

Fig. 3. Regional emissions separated for sources categories in 1990, 2000, 2030-CLE and 2030-MFR for CO [Tg CO $\left.\mathrm{yr}^{-1}\right]$.

scenario compared to CLE. We assume global emission controls for vehicles and off-road sources up to the EUROIV/EURO-V standard, for large stationary sources the application of selective catalytic reduction and for small stationary boilers the use of low- $\mathrm{NO}_{\mathrm{x}}$ burners. Obviously, the scope for further emission reductions strongly depends on the stringency of

the already implemented measures and thus differs greatly between countries. While there will be a limited potential for further reductions in Europe and North America, there remains significant scope in many developing countries. Sectoral emissions for the two scenarios as well as details by country/region are available from Cofala et al. (2005).

\subsubsection{Carbon monoxide}

In Fig. 1b we give an overview of the RAINS CO emissions. Biomass burning (not included in Fig. 1b) is a very important source for CO, as further discussed in Sect. 2.2. Our 


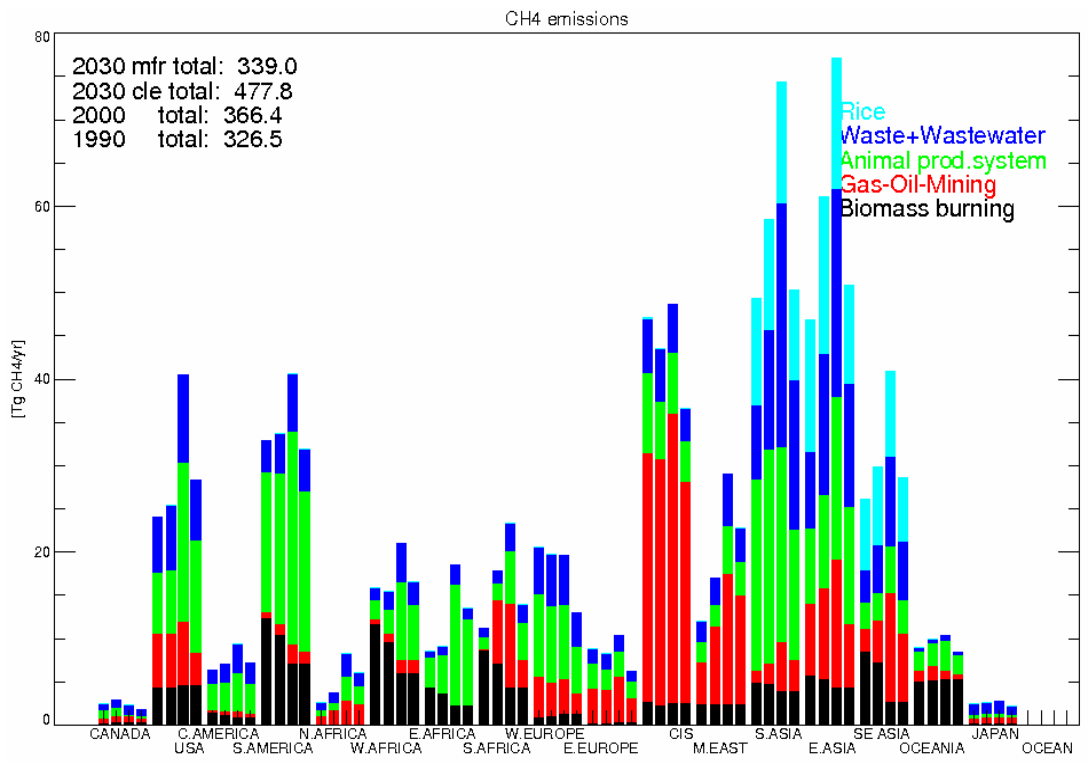

Fig. 4. Regional emissions separated for sources categories in 1990, 2000, 2030-CLE and 2030-MFR for $\mathrm{CH}_{4}\left[\mathrm{Tg} \mathrm{CH}_{4} \mathrm{yr}^{-1}\right]$.

analysis suggests, despite increasing economic activities, a global reduction of anthropogenic $\mathrm{CO}$ emissions in the coming three decades in both the CLE $(-15 \%)$ and MFR $(-53 \%)$ scenario. The highest decline $(-55 \%)$ occurs in Latin America, which is mainly due to a switch from fuel wood to other energy carriers in the residential sector. The only region with increasing emissions is Africa ( $+10 \%)$. The decoupling between economic growth and emissions is caused by the declining combustion of coal and fuel wood in households in small stoves and the penetration of three-way catalysts that reduce $\mathrm{CO}$ emissions from vehicles by typically between $80 \%$ and $90 \%$.

The maximum technically feasible reduction (MFR) scenario assumes full EURO-IV/EURO-V emission control standards for mobile sources, as well as good housekeeping measures on stationary combustion sources. However, this scenario does not consider possible reductions in energy demand (e.g., through energy efficiency measures) nor the potential offered by substitution of solid fuels by less polluting forms of energy. Based on these assumptions, the analysis suggests for 2030 a maximum reduction of $\mathrm{CO}$ emissions of $53 \%$ compared to the year 2000 . Similarly to $\mathrm{NO}_{\mathrm{x}}$, sectoral and country details can be found in Cofala et al. (2005).

\subsubsection{Methane}

In Fig. 1c we give an overview of the RAINS $\mathrm{CH}_{4}$ emissions. Our analysis suggests for the CLE case a continued increase of global anthropogenic $\mathrm{CH}_{4}$ emissions, leading to $35 \%$ higher emissions in 2030 than in 2000. Overall, emissions from all sectors are expected to grow due to increased economic activities and in the absence of wide-spread emission control measures. In contrast to the emissions of non- greenhouse gases $\mathrm{NO}_{\mathrm{x}}$ and $\mathrm{CO}$, the calculated growth in $\mathrm{CH}_{4}$ emissions is well within the range spanned by the SRES greenhouse gas scenarios.

A wide range of technical measures is presently available to reduce methane emissions. Such measures include the treatment of manure to generate biogas, different feedstock to prevent methane losses from enteric fermentation, prevention of waste disposal, controlling waste disposal sites, reduction in distribution losses of natural gas, gas recovery in coal mines as well as during oil and gas extraction, alternative rice strains, etc. (EPA, 1999; Hendriks et al., 1998). If all these "maximum technically feasible reductions" were applied to the full extent, global $\mathrm{CH}_{4}$ emissions would be reduced by $110 \mathrm{Tg} \mathrm{yr}^{-1}$ by 2030 . Country and sectoral details are to be found in Cofala et al. (2005).

\subsubsection{NMVOC}

RAINS did not include a separate assessment for NMVOC emissions. We assumed that the anthropogenic NMVOC emissions trends closely follow the development of CO emissions. This assumption is justified for mobile sources since three-way catalysts applied to mobile sources simultaneously reduce $\mathrm{CO}$ and NMVOC emissions with similar efficiency, but it may be less justified in other sectors, e.g., industrial emissions. Global emissions amount to ca. $250 \mathrm{Tg} \mathrm{yr}^{-1}$ in the year 2000 (including biomass burning), and 293 and $226 \mathrm{Tg} \mathrm{yr}^{-1}$ in the year 2030 for the CLE and MFR scenario, respectively (see also Sect. 7). 


\subsection{Other emissions}

For use in the TM3 and the STOCHEM CTM models, gridded emission data need to be provided. Thus, we allocated the national estimates for each sector according to the 1995 gridded sectoral distribution of emissions of the EDGAR3.2 global emission inventory (Olivier et al., 1999). We further linearly interpolated the data between the base years. Furthermore, the previously discussed IIASA emission data had to be supplemented with estimates for international seatraffic, aircraft emissions, biomass burning and natural emissions. The resulting emissions are provided in Figs. 2, 3, and 4 , giving a regional and a lumped sectoral break-down of the gridded anthropogenic $\mathrm{NO}_{\mathrm{x}}, \mathrm{CO}$ and $\mathrm{CH}_{4}$ emissions for the years 1990, 2000 and 2030 (the last for both CLE and MFR) using the IMAGE2.2 (http://arch.rivm.nl/image/) regional classification.

For sea traffic, we used the 1995 estimates provided in the EDGAR3.2 database and augmented them with a moderate growth rate of $1.5 \% \mathrm{yr}^{-1}$ over the time horizon of our study, without distinguishing between the CLE and MFR cases. The resulting emissions are consistent with the lower case projection developed by (Martinek, 2000). As we show in Fig. 2 sea-traffic already plays an important role for global NOx emissions, and may in future be larger than the emissions from any single region. Emissions from aircraft were only considered for $\mathrm{NO}_{\mathrm{x}}$ and were taken from the IPCC Special Report on Aviation and the Global Atmosphere (Isaksen et al., 1999). To address the stronger increase after 2015, we calculated a polynomial fit to the global emission numbers of 2.6 $\mathrm{Tg} \mathrm{NO}_{2} \mathrm{yr}^{-1}$ in the year 2000, and 5.7 Tg $\mathrm{NO}_{2} \mathrm{yr}^{-1}$ in 2030 and applied them for both scenarios.

For emissions from biomass burning we used the EDGAR3.2 1990 and 1995 amounts and spatial distributions for savannah burning, deforestation fires, agricultural waste burning and temperate forest fires. To account for more recent insights regarding emission factors and activity data (Arellano et al., 2004; Bergamaschi et al., 2000b; Van der Werf et al., 2003) we doubled these amounts leading in the year 2000 to global biomass burning emissions of $27 \mathrm{Tg} \mathrm{NO}_{2} \mathrm{yr}^{-1}, 575 \mathrm{Tg} \mathrm{CO} \mathrm{yr}-1,65 \mathrm{Tg} \mathrm{CH}_{4} \mathrm{yr}^{-1}$, and $80 \mathrm{Tg}$ NMVOC $\mathrm{yr}^{-1}$. These numbers are on the high side of the estimates given by e.g. (Andreae and Merlot, 2001), but it should be noted that exact amounts of biomass burning are not well established and subject to large inter-annual fluctuations. The biomass burning source is most critical for the CO budget (http://www.sdearthtimes.com/et0701/ et0701s12.html; Wild et al., 2001). Also note that in IPCC

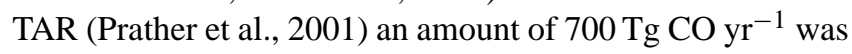
recommended, $25 \%$ higher than in this study. In accordance with the assumptions made in the IIASA MESSAGE implementation of the B2 scenario the emissions from deforestation are gradually declining to zero in the year 2020 (for both CLE and MFR). In contrast, the by far larger emissions from savannahs and high latitude fires remained almost constant.
In S. America, and large parts of Africa, $\mathrm{NO}_{\mathrm{x}}$ emissions are dominated by biomass burning, whereas industrial and traffic emissions dominate in the US, Europe and Asia (Fig. 2). Figure 3 shows the important role of biomass burning related $\mathrm{CO}$ emissions in Africa, Oceania, and South America. It should be noted that the biomass burning emissions are very uncertain and that the use of EDGAR3.2 emissions results in quite high $\mathrm{CO}$ emissions at Northern Latitudes, compared to e.g. more recent emission databases (Van der Werf et al., 2003). Biofuel is an important source for CO in Asia, whereas industrial and traffic emissions dominate in Europe, USA and Japan. Fig. 4 displays the variable importance of different $\mathrm{CH}_{4}$ sources in the world regions: Rice production and waste dominate in Asia, gas-oil and mining in Russia and the Middle East, whereas waste and animal production systems dominate methane emissions in the US, S. America, and Europe.

For natural emissions we consider $\mathrm{NO}_{\mathrm{x}}$ emissions from soils and lightning (ca. $38 \mathrm{Tg} \mathrm{NO}_{2} \mathrm{yr}^{-1}$, $\mathrm{CO}$ emissions from

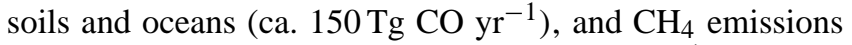
from wetlands and termites (ca. $240 \mathrm{Tg} \mathrm{CH}_{4} \mathrm{yr}^{-1}$ ), and minor sources ( $<10 \mathrm{Tg} \mathrm{C} \mathrm{CH}_{4} \mathrm{yr}^{-1}$ ) from permafrost melting, volcanoes and oceans. The natural NMVOC emissions are predominantly isoprene emissions from vegetation $(507 \mathrm{Tg}$

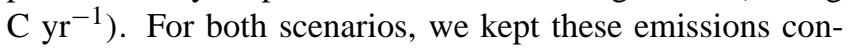
stant over time. Some of the emissions are dependent on the model's meteorology and differ slightly among the models and years (see Sect. 3).

\section{The Atmospheric Chemistry Transport models}

In this study we used the Lagrangian model STOCHEM and the Eulerian model TM3, which have been used extensively to assess aspects of the tropospheric methane and ozone cycles, and also participated in the IPCC Third Assessment (IPCC, 2001).

\subsection{The TM3 model}

The Eulerian global chemistry-transport model TM3 (Dentener et al, 2003a, and references therein) has been used in this study at a spatial resolution of $10^{\circ}$ longitude and $7.5^{\circ}$ latitude with 19 vertical layers, with approximately 14 layers in the troposphere. In this study the model used annually repeated 1990 meteorological fields from the ECMWF ERA15 re-analysis (Gibson et al., 1997). These fields include global distributions for horizontal wind, surface pressure, temperature, humidity, cloud liquid water content, cloud ice water content, cloud cover, large-scale and convective precipitation provided in 3-6 h time steps. In a pre-processing chain these fields were used to calculate turbulent diffusion coefficients according to (Louis, 1979) and convective mass fluxes using a modified Tiedtke scheme (Tiedtke, 1989) that accounts for shallow, mid-level and deep convection. Tracer advection 
Table 1. List of Simulations by TM3 and STOCHEM.

\begin{tabular}{|c|c|c|}
\hline Emission scenario & Model & Meteorology \\
\hline CLE & TM3 & ECMWF 1990 \\
\hline CLE & STOCHEM & HadAM3 fixed SST \\
\hline MFR & TM3 & ECMWF 1990 \\
\hline MFR & STOCHEM & HadAM3 fixed SST \\
\hline MFR-CH ${ }_{4}$ : for $\mathrm{CH}_{4}$, here CO-NMVOC-NO ${ }_{\mathrm{x}}$ : CLE & TM3 & ECMWF 1990 \\
\hline MFR-pol: CO-NMVOC-NO ${ }_{x}$, whereas $\mathrm{CH}_{4}$ :CLE & TM3 & ECMWF 1990 \\
\hline
\end{tabular}

is described with the slopes scheme of Russell and Lerner (1981). The chemical scheme is a modified Carbon Bond Mechanism4 (Gery et al., 1989) mechanism that describes $\mathrm{CH}_{4}$-CO-NMVOC-NO $\mathrm{N}_{\mathrm{x}}-\mathrm{SOx}$ chemistry (Houweling et al., 1998) and considers 47 species, and 91 reactions. Photolysis rates are parameterized following Krol and Weele (1997); it accounts for the influence of clouds, but does not include interactions with aerosol. The chemical equations are solved with an Backward Euler Iterative Solver (Hertel et al., 1993), using a time step of $40 \mathrm{~min}$. The removal of soluble trace gases and aerosol by wet deposition is based on the work of Guelle et al. (1998) and Jeuken et al. (2001) and accounts for wet removal in and below cloud in stratiform and convective rain. Dry deposition follows a resistance approach and is described by Ganzeveld et al. (1998). Stratospheric boundary conditions for ozone and $\mathrm{HNO}_{3}$ were relaxed to satellite observations above $50 \mathrm{hPa}$ as described in Lelieveld and Dentener (2000). Effectively, about $520 \mathrm{Tg} \mathrm{O}_{3} \mathrm{yr}^{-1}$ enters the troposphere through the $100 \mathrm{hPa}$ level. $\mathrm{CH}_{4}$ stratospheric loss rates were prescribed at a fixed rate of $40 \mathrm{Tg} \mathrm{CH}_{4} \mathrm{yr}^{-1}$, and the $\mathrm{CH}_{4}$ soil sink kept constant at $30 \mathrm{Tg} \mathrm{CH}_{4} \mathrm{yr}^{-1}$. We showed before that the model realistically simulates Radon222 (Dentener et al., 1999), tropospheric ozone (Houweling et al., 1998; Lelieveld and Dentener, 2000; Peters et al., 2001) and methane (Dentener et al., 2003b; Houweling et al., 2000a). A recent study was devoted to study $\mathrm{OH}$ trends (Dentener et al., 2003a) and is in particular relevant for this study, since that model set-up was used almost unchanged in the present study.

\subsection{The STOCHEM model}

STOCHEM is Lagrangian tropospheric chemistry-transport model, originally described by Collins et al. (1997). In this study the atmosphere is divided in 50000 air parcels that are mapped after each advective time-step to a 5 by 5 degree resolution grid with 9 vertical layers of $100 \mathrm{hPa}$ thickness. Input meteorology is provided by the atmosphere-only climate model HadAM3 (Pope et al., 2000) at a standard resolution of 3.75 longitude and 2.5 latitude with 19 vertical levels extending to $10 \mathrm{hPa}$. The HadAM3 time-step is $30 \mathrm{~min}$, with meteorological fields passed to STOCHEM every $3 \mathrm{~h}$.
HadAM3 was forced with monthly mean sea surface temperature (SST) climatology for the period 1978-1996 (Taylor et al., 2000); these fields have a seasonal structure, but are annually invariant. Land surface temperatures, and consequently also the windfields, are calculated by the GCM and show some inter-annual variability. Turbulent mixing in the boundary layer is achieved by randomly re-assigning the vertical co-ordinates of air parcels over the depth of the planetary boundary layer height, which is provided by the HadAM3 model. Convective mixing uses updraft and detrainment fluxes from HadAM3 as described by Collins et al. (2002). Air parcel advection is performed using a fourth order Runge-Kutta method; at each $1 \mathrm{~h}$ advection time step the winds are linearly interpolated to the parcel's location in the horizontal and using cubic interpolation in the vertical. The chemical scheme, as described by Collins et al. (1999) includes 70 species that take part in 174 photochemical gas and aqueous phase reactions. The chemical scheme uses a Backward Euler solver (Hertel et al., 1993) using a time step of $5 \mathrm{~min}$. Wet deposition operates on all soluble species, with scavenging coefficients taken from (Penner et al., 1994). The scheme is described in more detail in Stevenson et al. (2003). Dry deposition follows a resistance approach as described by Sanderson et al. (2003) including explicit description of the $\mathrm{CH}_{4}$ soil sink. Ozone and $\mathrm{NO}_{\mathrm{y}}$ upper boundary conditions are imposed by prescribing fluxes into the top layer of the model at $100 \mathrm{hPa}$. For this vertical winds derived from HadAM3 at $100 \mathrm{hPa}$ were used together with the ozone climatology of Li and Shine (1995). The resulting ozone flux into the model domain amounts to $420 \mathrm{Tg} \mathrm{O}_{3} \mathrm{yr}^{-1}$ (Stevenson et al., 2004). $\mathrm{NO}_{\mathrm{y}}$ influxes were fixed to those of $\mathrm{O}_{3}$ by assuming a fixed mass ratio of $\mathrm{N}: \mathrm{O}_{3}$ of $1: 1000 . \mathrm{CH}_{4}$ stratospheric loss rates were prescribed following Prather et al. (2001).

As described above STOCHEM and TM3 represent different types of models using very different parameterizations and meteorological input datasets. In the next section we will document some salient features of model performance to show that the combination of the models set-up and emissions is realistically describing global scale measurements of ozone, methane and carbon monoxide. 

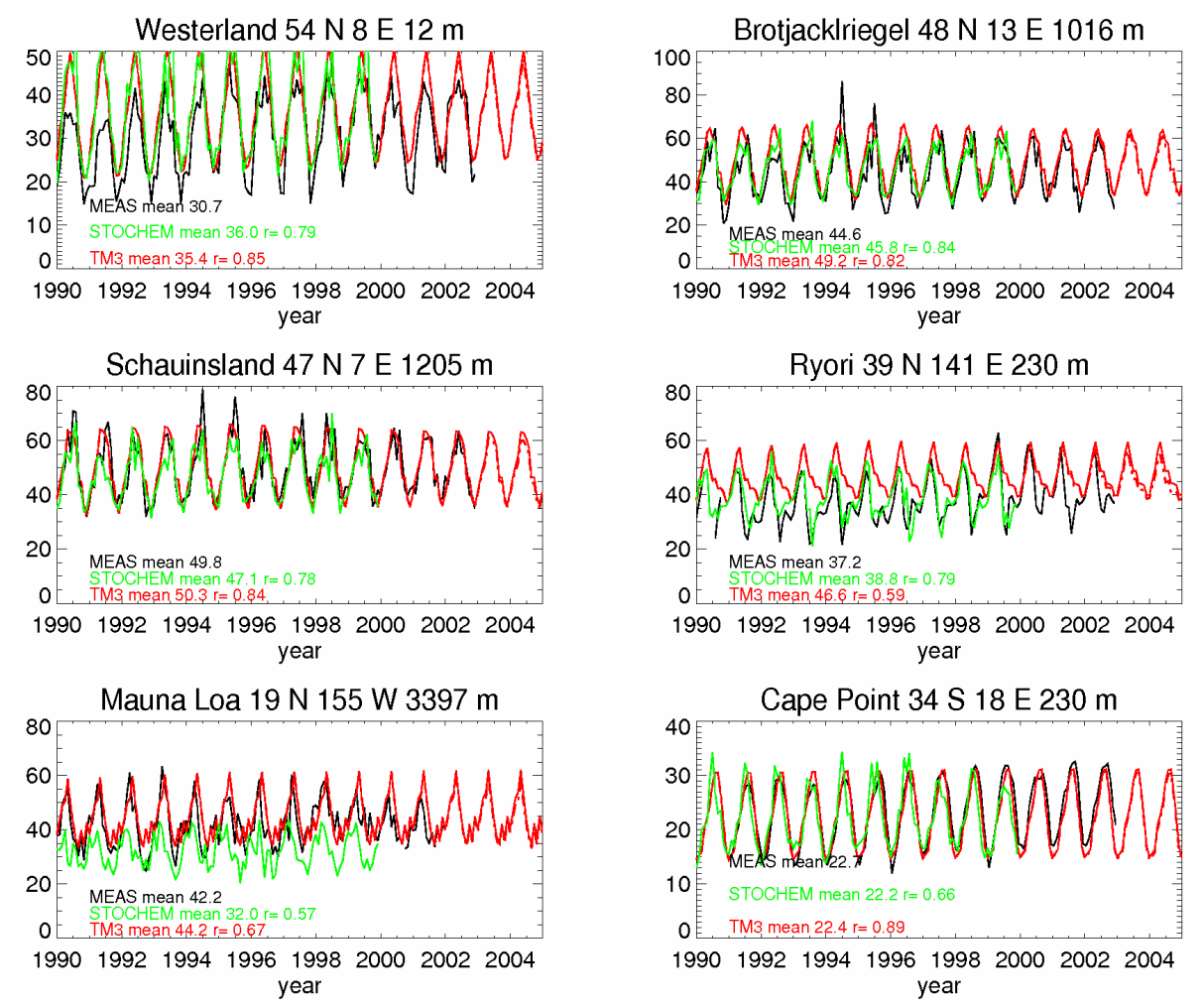

Fig. 5. Surface ozone [ppbv] measured at 6 background stations and modelled by TM3 and STOCHEM. Model results were interpolated to location and altitude of station.

\section{Simulations}

\subsection{Description of simulations}

In order to simulate the future developments of ozone and methane we performed a set of 4 scenario calculations, summarized in Table 1. The scenarios were integrated from 1990-2030, using a spin-up of 13 months for STOCHEM and 24 months for TM3, respectively. Both TM3 and STOCHEM used CLE and MFR scenarios, the sensitivity studies MFR- $\mathrm{CH}_{4}$ (which considers MFR for $\mathrm{CH}_{4}$, but CLE for the other gases) and MFR-pol (MFR for $\mathrm{CO}, \mathrm{NO}_{\mathrm{x}}$, and NMVOC) were computed using TM3 only.

\subsection{Comparison with measurements}

Although in previous applications of the TM3 and STOCHEM models extensive comparison to measurements has been made, in this work we use a completely new set of emissions. In this section we show a selection of measurements to demonstrate that the 1990-2003 part of our simulations are consistent with current observations and can be used to extrapolate to future conditions. For analysis, we divide the globe into four latitude bands, stretching from $90^{\circ} \mathrm{S}-$ $45^{\circ} \mathrm{S}, 45^{\circ} \mathrm{S}$-Equator, Equator- $45^{\circ} \mathrm{N}$, and $45^{\circ} \mathrm{N}-90^{\circ} \mathrm{N}$.

\subsubsection{Surface ozone}

In Fig. 5 we present surface ozone calculated by TM3 and STOCHEM at 6 stations, mostly located in the NH. Data were retrieved from the world data center for surface ozone (WDSO) (http://gaw.kishou.go.jp/wdegg.html), with the additional data for Cape Point kindly provided by Dr. E. Brunke. The WDCO data sets appear quite heterogeneous, and those that cover the entire 1990s are scarce. We selected background stations that our relatively coarse models should be able to represent. Thus stations that may be strongly influenced by local emissions were not considered. No selection of data was applied. Generally the TM3 and STOCHEM models represent relatively well the set of background stations given in Fig. 5, with correlation coefficients based on monthly ozone ranging between 0.6 and 0.85 . Of course there are also some discrepancies: especially at continental stations the difference of models with measurements can be of the order of $10 \mathrm{ppbv}$; this can be explained from uncertainties in emissions, chemistry and especially the coarse model resolution chosen for the scenario simulations. No strong trends are visible in either the models or the measurements over the time period considered. Note that the difference of the ozone signal in summer between these two scenarios is about 10 ppbv by the year 2010 (not shown). 
4.2.2 Tropospheric ozone in the middle and upper troposphere

In order to evaluate model performance in the middle and upper troposphere, we use the ozone climatology compiled by Logan (1999) based on an analysis of ozone soundings obtained predominantly during the period 1985-1995. About 55 stations were selected; 3 stations were located in the region $90 \mathrm{~S}-45 \mathrm{~S}, 20$ in the region $45 \mathrm{~S}$-Equator, 19 stations from the Equator- $45 \mathrm{~N}$, and 13 stations from $45 \mathrm{~N}$ to $90 \mathrm{~N}$. Monthly average model results for the period 1990-2000 were interpolated to the geographical station location and pressures. In Figs. 6a and $\mathrm{b}$ we display results obtained at $800 \mathrm{hPa}$ and $400 \mathrm{hPa}$, respectively. The error bars represent the standard deviations of the set of individual soundings contributing to the regional average, rather than the interannual variability within the individual measurements contributing to the monthly averages. We present our results in this way, since we compare model results obtained using meteorology for a specific year, 1990 in the case of TM3, or a decade of climate model calculated years for STOCHEM, and compare them to measurements representative for other years.

At $800 \mathrm{hPa}$ in the SH both TM3 and STOCHEM underestimate ozone by $5-10 \mathrm{ppbv}$. In the other latitude bands both TM3 and STOCHEM reproduce the seasonal cycle of $\mathrm{O}_{3}$ well within the standard deviation of the measurements. At $400 \mathrm{hPa}$ in the middle/upper troposphere TM3 generally realistically reproduces the measurements, whereas STOCHEM under predicts $\mathrm{O}_{3}$ by $10-15 \mathrm{ppbv}$. However, especially in the $45 \mathrm{~S}-90 \mathrm{~S}$ region in summer TM3 also underestimates ozone. The problem seems related to the amount of stratosphere-troposphere exchange, and the exact height of the tropopause, since the observed concentrations and variability indicated the influence of stratospheric air, whereas TM3 rather calculates tropospheric ozone values and variability. Nevertheless, all in all both models give a realistic picture of ozone above the boundary layer.

\subsubsection{Carbon monoxide}

Figure 7 displays the annual averaged $\mathrm{CO}$ measurements and model results for the four world latitude bands. We use the monthly mean NOAA CMDL measurements (http: //www.cmdl.noaa.gov/), as reported by, e.g., (Dlugokencky et al., 1996; Dlugokencky et al., 2003). We used only those stations with a complete dataset for the period 1994-2002, and averaged them in 4 latitude bands and annual averages. The TM3 and STOCHEM model results interpolated to the geographical location and altitude of the stations were averaged in the same way. In the SH TM3 overestimates $\mathrm{CO}$ by about $5-15$ ppbv. In the NH TM3 calculated CO levels correspond accurately to the measurements, whereas the STOCHEM CO levels were underestimated by up to $15-30 \%$
(10-20 ppbv) in the $\mathrm{NH}$, and up to $50 \mathrm{ppbv}$ in the high latitude zones.

We also present the standard deviations of the annual model concentrations and measurements, representing the spatial variability among stations in a particular year. Both in the $\mathrm{NH}$ and $\mathrm{SH}$ the measured and modelled error bars are similar, meaning that the gradients of $\mathrm{CO}$ close to the continents and on the ocean are well captured. In the $\mathrm{NH}$ in 1998 measurements on average were elevated by $10-20 \mathrm{ppbv}$ compared to other years. This increase is related to large scale biomass burning in Indonesia (Duncan et al., 2003) following the intensive El Niño of 1997/1998, and large forest fires in Canada and Siberia (Simmonds et al., 2004; Wotawa et al., 2001; Yurganov et al., 2004]. This signal is not seen in STOCHEM and TM3 since we did not account for inter-annual variations in biomass burning. As indicated in Sect. 2.4 the uncertainties in the biomass burning emissions are large. Since the inter-annual variability in the CO measurements is high, it is at this moment not possible to confirm whether the decreasing $\mathrm{NH}$ model trend in the period 1995-2002 is realistic. The decreasing model trend, however, seems to be found by measurements at e.g. Mace Head, that indicate a decreasing trend of $1.13 \mathrm{ppbv} / \mathrm{yr}$ in baseline air masses (Simmonds et al., 2004). Models and measurements agree on the absence of a $\mathrm{CO}$ trend in the $\mathrm{SH}$.

\subsubsection{Methane}

We present annual average methane concentrations for the four world latitude bands in Fig. 8. As for $\mathrm{CO}, \mathrm{CH}_{4}$ measurements were obtained from the NOAA CMDL network; since more measurements were available we could use the full record for 1990-1998. Both models were independently initialized with previously calculated $\mathrm{CH}_{4}$ fields for the year 1987. Due to unforeseen inaccuracies in the initialization, TM3 $\mathrm{CH}_{4}$ is about 30-40 ppbv lower than the measurements, whereas STOCHEM is about $30 \mathrm{ppbv}$ higher. We estimate that the influence of this inaccuracy of the initial $\mathrm{CH}_{4}$ concentrations on global $\mathrm{OH}$ is of the order of $1 \%$ (using the feedback factor of $d \ln [\mathrm{OH}] / d \ln \left[\mathrm{CH}_{4}\right]=-0.32$ (Prather et al., 2001). This is small in comparison to overall uncertainties of global OH. In the 1990s the measured methane growth rates were highly variable, ranging from 0 to $15 \mathrm{ppbv} \mathrm{yr}^{-1}$ (Butler et al., 2004; Dentener et al., 2003b; Dlugokencky et al., 2003; Prather et al., 2001) with an average trend of $8 \mathrm{ppbv} \mathrm{yr}^{-1}$.

Although this variability of growth rates is not represented by our models, the average methane increases in the period 1990-2002 are well represented by the model, despite the somewhat lower trend of TM3 at the beginning of the 1990s. After the year 1998 both TM3 and STOCHEM predict a too high trend. Interestingly, after the year 2000 the use of the MFR emission scenario seems to agree better with the measured trend than CLE, although shifted by two or three years. 

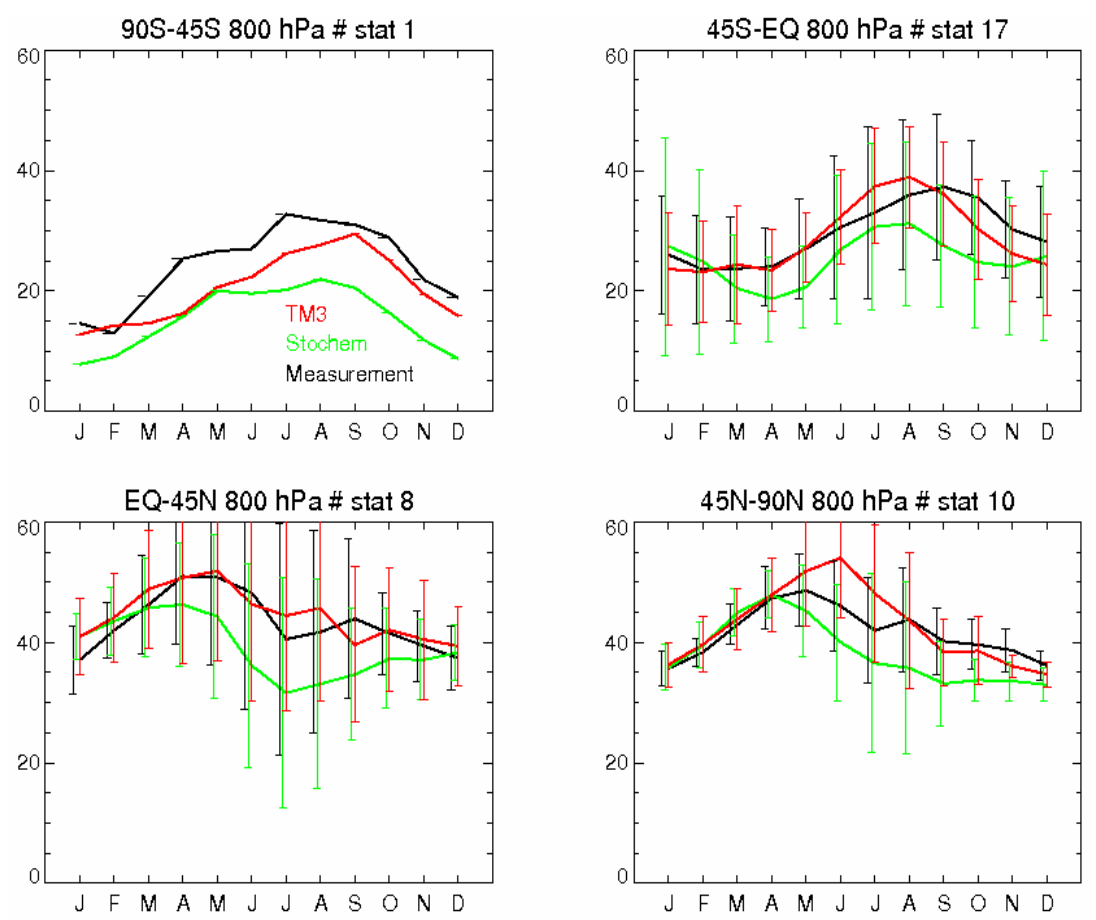

Fig. 6a. Comparison of free tropospheric ozone calculated with TM3 and STOCHEM to ozone soundings averaged for 4 latitude bands at $800 \mathrm{hPa}$. The number of stations included in the analyses is mentioned in the figure heading.
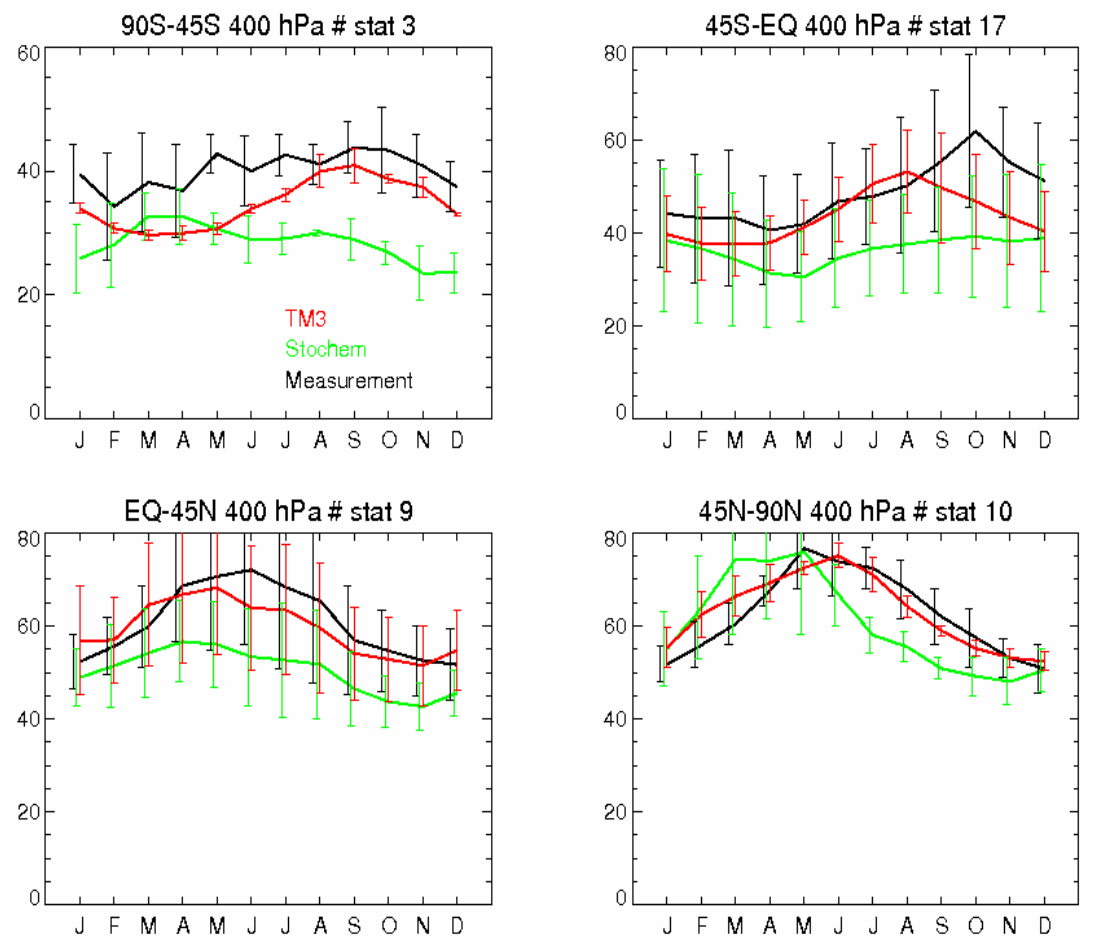

Fig. 6b. Comparison of free tropospheric ozone calculated with TM3 and STOCHEM to ozone soundings averaged for 4 latitude bands at $400 \mathrm{hPa}$. 

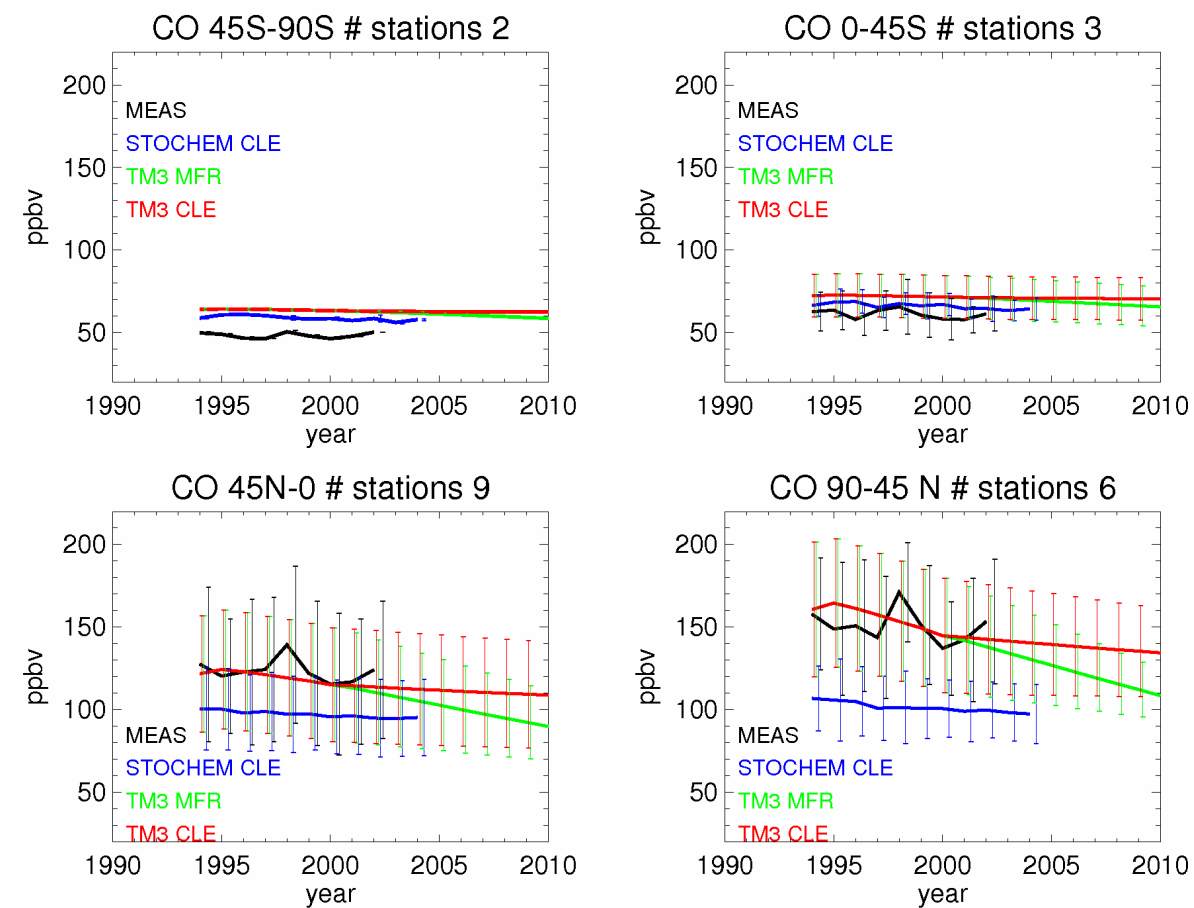

Fig. 7. Comparison of annual average CO calculated with TM3 and STOCHEM at station locations to NOAA CMDL measurements averaged for 4 latitude bands. Error bars indicate the modelled and measured spatial variability of the stations. The number of stations included in the analyses is mentioned in the heading.
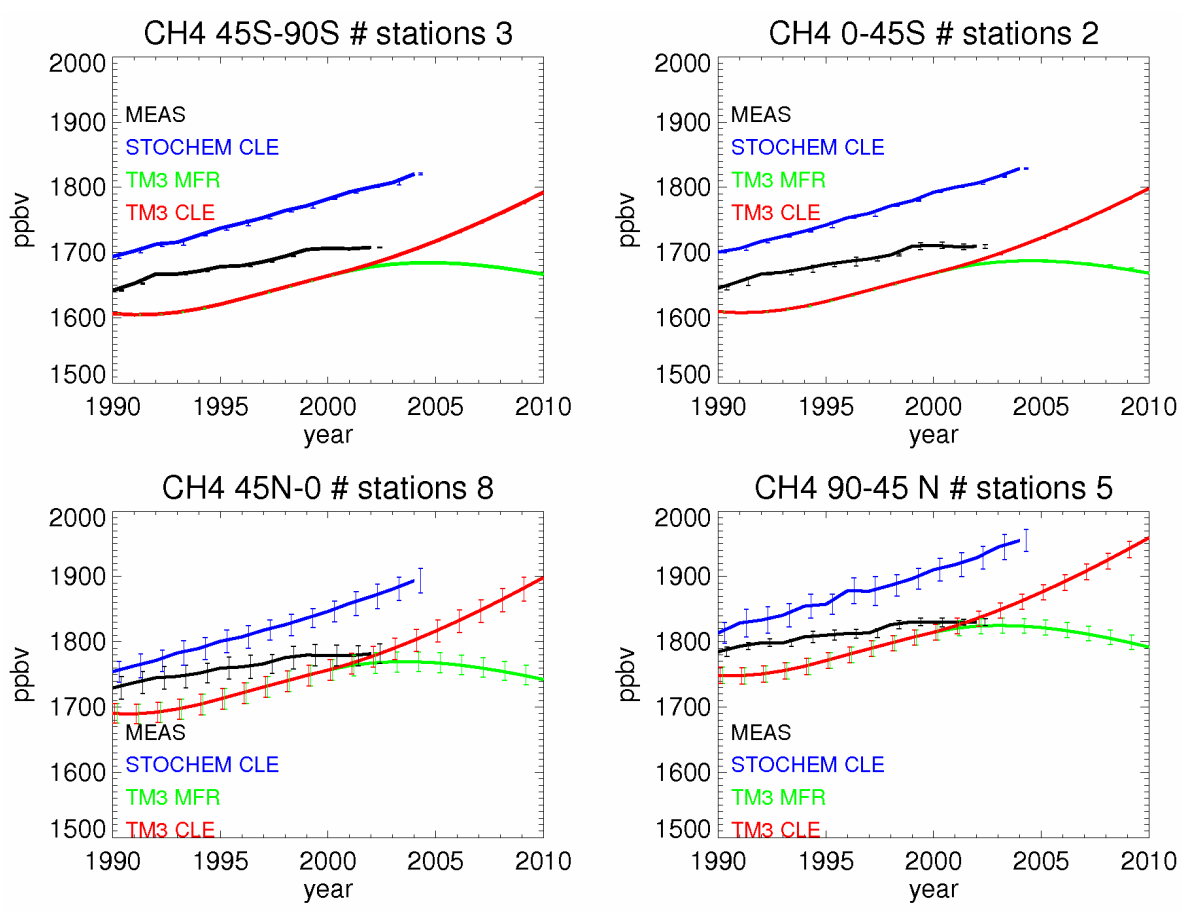

Fig. 8. Comparison of annual average surface $\mathrm{CH}_{4}$ calculated with TM3 and STOCHEM taken at station locations to NOAA CMDL measurements averaged for 4 latitude bands. Error bars indicate the modelled and measured spatial variability of the stations. The offsets are due to different initializations. 


\section{Scenario calculations}

\subsection{Atmospheric burdens of $\mathrm{CH}_{4}, \mathrm{CO}, \mathrm{OH}$ and $\mathrm{O}_{3}$}

\subsubsection{Burdens for 2000}

The burdens for TM3 and STOCHEM for the four latitude bands in the year 2000 are presented in Table 2. As was also visible in the surface $\mathrm{CH}_{4}$ concentrations (Fig. 8), the TM3 $\mathrm{CH}_{4}$ burdens are somewhat lower than those of STOCHEM, mainly resulting from the initialization. Both models produce similar levels and trends in CO burdens for the 1990s, except in the $45 \mathrm{~N}-90 \mathrm{~N}$ compartment, were we showed before that STOCHEM underestimated CO by ca. $15-30 \%$, possibly related to larger $\mathrm{OH}$ burdens. The global $\mathrm{O}_{3}$ burdens calculated by TM 3 are $15 \%$ higher than those of STOCHEM; the difference mainly occurs in the tropics and SH. There are many processes that can explain the model differences, but one important one is the difference in our parameterizations of convection, strongly influencing the lifetime of ozone in the tropics. The STOCHEM results clearly show inter-annual variability, mainly resulting from variability in the stratosphere-troposphere exchange processes, which are partly driven by HadAM 3 vertical winds at $100 \mathrm{hPa}$. As explained before, in HadAM3 only SSTs were kept constant, whereas land surface temperatures were not constrained, leading to inter-annual variability of meteorology. In contrast TM3 always used the meteorology representative for the year 1990. There is disagreement between the models on global $\mathrm{OH}$ burdens. Globally, STOCHEM calculates about $25 \%$ more $\mathrm{OH}$ burden than TM3, because of differences in water vapor, photo-dissociation rates, and $\mathrm{OH}$ production and loss in the free troposphere. Despite the differences in $\mathrm{OH}$ burden, global $\mathrm{CH}_{4}$ lifetimes are similar in the year 2000. This can be explained by the fact that the destruction of $\mathrm{CH}_{4}$ is mostly sensitive to the high $\mathrm{OH}$ concentrations in the humid and warm tropical regions, and is not particularly sensitive to middle and upper tropospheric and extra-tropical OH (Dentener et al., 2003a).

\subsubsection{Burden and lifetime trends}

In Fig. 9 we present the calculated global $\mathrm{CH}_{4}$ lifetime with regard to oxidation by $\mathrm{OH}$, and the atmospheric burdens of $\mathrm{CH}_{4}, \mathrm{CO}, \mathrm{O}_{3}$ and $\mathrm{OH}$ integrated up to $100 \mathrm{hPa}$. Results are presented for simulations the CLE and MFR scenarios for TM3 and STOCHEM, and MFR- $\mathrm{CH}_{4}$ and MFR-pol for TM3. $100 \mathrm{hPa}$ corresponds to the tropical tropopause, and hence the burdens contain some stratospheric air at middle and high latitudes. Note that for the period 1990-2000 the simulated results for all scenarios are identical. To visually highlight the model trends, rather than model differences, we normalized in Fig. 9 the STOCHEM results to match the TM3 results of the year 2000. In the following discussion we will use these normalized numbers.
The global $\mathrm{CH}_{4}$ burdens for the CLE case increase from $4300 \mathrm{Tg}$ in the year 2000 to $5300 \mathrm{Tg}$ in 2030 for TM3, and to $5000 \mathrm{Tg}$ for STOCHEM. The increases of methane burdens correspond to roughly $1750 \mathrm{ppbv}$ in the year 2000 and 2200 ppbv (TM3) and 2090 ppbv (STOCHEM) for CLE.

For the MFR case, both models calculate methane burdens stabilizing at $4300 \mathrm{Tg}$. Considering $\mathrm{MFR}-\mathrm{CH}_{4}$ where only methane emissions are reduced but $\mathrm{NO}_{\mathrm{x}}, \mathrm{CO}$ and NMVOC emissions develop according to CLE, the global methane burden would decrease by $1000 \mathrm{Tg}$ below the CLE level calculated for 2030. Alternatively, assuming maximum feasible reductions for $\mathrm{NO}_{\mathrm{x}}, \mathrm{NMVOC}$ and $\mathrm{CO}$ but leaving $\mathrm{CH}_{4}$ at the CLE development (simulation MFR-pol) would in 2030 increase the global methane burden by $400 \mathrm{Tg}$ above the CLE case. This increased $\mathrm{CH}_{4}$ burden resulting from the same $\mathrm{CH}_{4}$ emissions is caused by the prolonged lifetime of methane due to lower availability of $\mathrm{OH}$ radicals that serve as $\mathrm{CH}_{4}$ sinks. $\mathrm{OH}$ is reduced as a consequence of the lower $\mathrm{NO}_{\mathrm{x}}, \mathrm{CO}$ and NMVOC emissions. Despite the differences in methane burden in STOCHEM and TM3 (Table 2), and possible consequences for $\mathrm{OH}$, the temporal changes of methane lifetime and burden are very similar in TM3 and STOCHEM. In both models, the calculated $\mathrm{CH}_{4}$ lifetime trends (Fig. 9) indicate a rather stable $\mathrm{CH}_{4}$ lifetime in the next decades for both the CLE and MFR scenario. However, the TM3 calculations show that preferential air pollution controls MFRpol tend to lengthen the methane lifetime, whereas the MFR$\mathrm{CH}_{4}$ case has an opposite effect. The latter effect is a manifestation of the methane self-feedback (Isaksen and Hov, 1987) where increases in methane reduce tropospheric $\mathrm{OH}$, which in turn increases methane.

Both models suggest for the CLE case stable global CO burdens at approximately $\sim 380 \mathrm{Tg}$ (CLE), and a gradual decrease to $320 \mathrm{Tg} \mathrm{CO}$ in 2030 for the MFR case.

The global $\mathrm{O}_{3}$ burdens from TM3 and STOCHEM show very similar increases from $450 \mathrm{Tg}$ in 1990 to $470-485 \mathrm{Tg}$ in 2030 in the current legislation (CLE) case, and decreases to $430 \mathrm{Tg}$ for the MFR case. Further note the burdens calculated in this work are up to $100 \mathrm{hPa}$. The tropospheric $\mathrm{O}_{3}$ burdens in the year 2000, when the extra-tropical lower stratosphere are excluded, are lower by ca. 120-130 Tg (Houweling et al., 1998; Stevenson et al., 2004, Table 2).

Despite the large discrepancies in the $2000 \mathrm{OH}$ burdens, both models agree on stable $\mathrm{OH}$ burdens for both the CLE and MFR scenarios. It is interesting to note here that the MFR- $\mathrm{CH}_{4}$ and MFR-pol simulations, calculated with TM3, affect the $\mathrm{OH}$ burdens more strongly than the "balanced" CLE and MFR simulations. Similar compensating effects have found when assessing the change of $\mathrm{OH}$ from the preindustrial to the present time (Lelieveld and Dentener, 2000; Wang and Jacob, 1998). 
Table 2. Burdens of $\mathrm{CH}_{4}, \mathrm{CO}, \mathrm{O}_{3}[\mathrm{Tg}]$ and $\mathrm{OH}[\mathrm{Mg}]$ determined from surface to $100 \mathrm{hPa}$ in the year 2000. We show data for four latitude bands and globally for TM3 and STOCHEM. Also given the lifetime with respect to $\mathrm{OH}$ of $\mathrm{CH}_{4}$ [years].

\begin{tabular}{ccccccccccc}
\hline \multirow{2}{*}{ Region } & \multicolumn{2}{c}{$\mathrm{CH}_{4}$ lifetime } & \multicolumn{2}{c}{$\mathrm{CH}_{4}$ burden } & \multicolumn{2}{c}{$\mathrm{CO}$ burden } & \multicolumn{2}{c}{$\mathrm{O}_{3}$ burden } & \multicolumn{2}{c}{ OH burden } \\
& TM3 & STO & TM3 & STO & TM3 & STO & TM3 & STO & TM3 & STO \\
\hline 90 N-45 N & 28.7 & 20.4 & 645 & 697 & 75 & 59 & 111 & 121 & 10 & 19 \\
45 N-EQ & 6.7 & 6.3 & 1533 & 1652 & 152 & 146 & 147 & 120 & 79 & 108 \\
EQ-45 S & 7.6 & 8.2 & 1510 & 1648 & 120 & 121 & 127 & 90 & 76 & 86 \\
45 S-90 S & 50.8 & 66.8 & 583 & 645 & 39 & 37 & 77 & 60 & 8.1 & 8.2 \\
Global & 9.2 & 9.2 & 4272 & 4639 & 386 & 362 & 462 & 392 & 173 & 222 \\
\hline
\end{tabular}
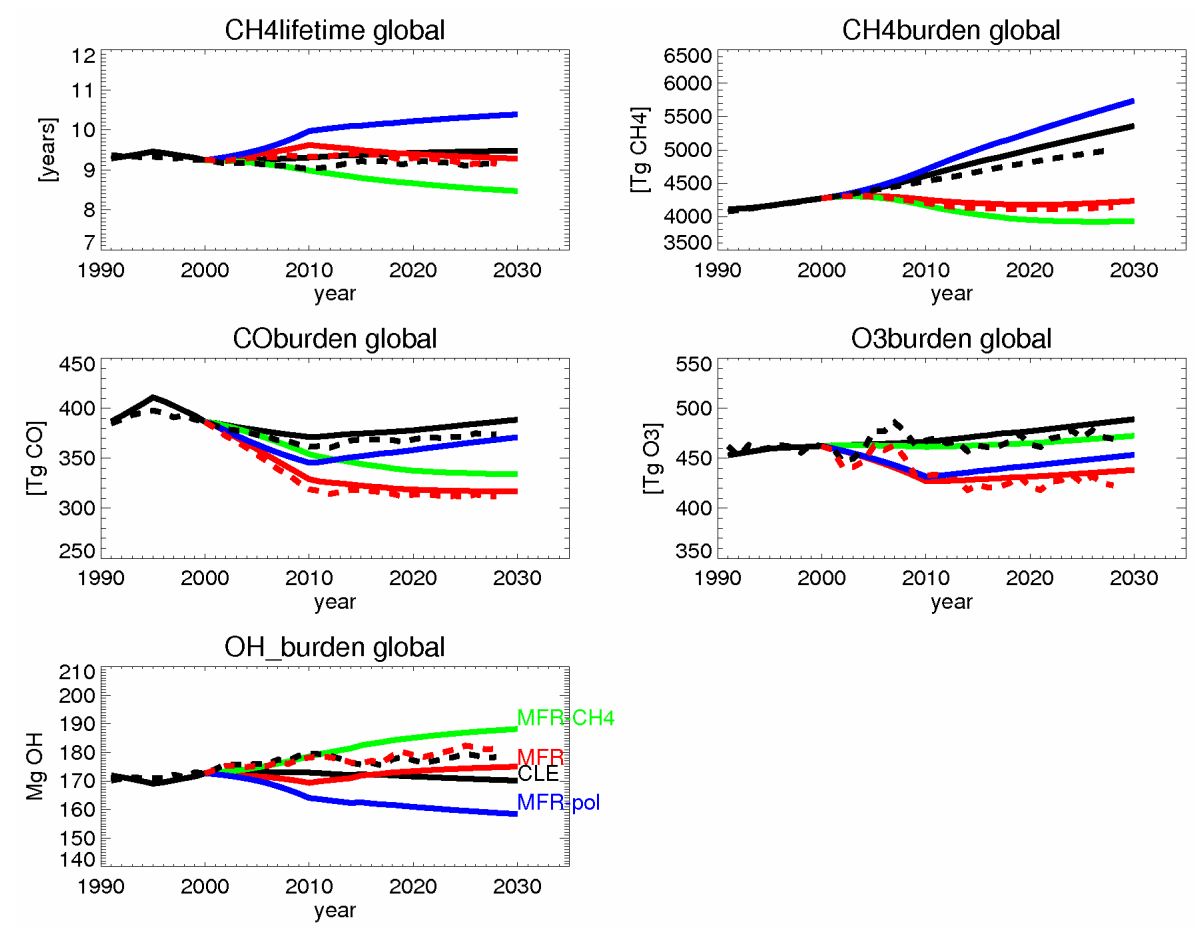

Fig. 9. Global trends for the period 1990-2030 calculated with TM3 (solid) for the four scenarios, and STOCHEM (dashed) for CLE and MFR for $\mathrm{CH}_{4}$ lifetime [years], $\mathrm{CH}_{4}$ burden [Tg $\mathrm{CH}_{4}$ ], $\mathrm{CO}$ burden [Tg CO], $\mathrm{O}_{3}$ burden [Tg $\mathrm{O}_{3}$ ], and $\mathrm{OH}$ burden [Mg OH]. Results are normalized for the year 2000 .

\subsection{Surface Ozone in the 1990s and 2020s}

In this section we explore the regional changes in surface ozone for the various scenarios, which are of importance for air pollution issues. We focus on annual average ozone averaged for the 1990-2000 decade, and the 2020-2030 decade. Results of the NH summer season (JJA) are presented in the ACPD version of this paper (Dentener et al., 2004).

In Fig. 10 we present the annual average computed ozone concentrations at the surface averaged for the 1990s, while Fig. 11a-c focuses on the difference between the 2020s and 1990s. For the 1990s, with few exceptions, the models show broad agreement on the regional patterns of surface ozone concentrations, although the STOCHEM model consistently calculates 5 to 10 ppbv higher ozone levels over the continents and lower values over the oceans. Average volume mixing ratios range from 30 to $60 \mathrm{ppbv}$. The high concentrations calculated over the Himalayas are due to high altitude of this region, and strong mixing with stratospheric air contributing $25 \%$ to the surface ozone levels. The biomass burning signal in tropical Africa is much stronger in STOCHEM than in TM3, probably due to differences in the mixing schemes of the two models, or in the different geographical and temporal distributions of biomass burning emissions in our models. It is likely that biomass burning emissions are partly released at higher altitudes, leading to more effective ozone production, as implicitly included in STOCHEM, but not in TM3. 


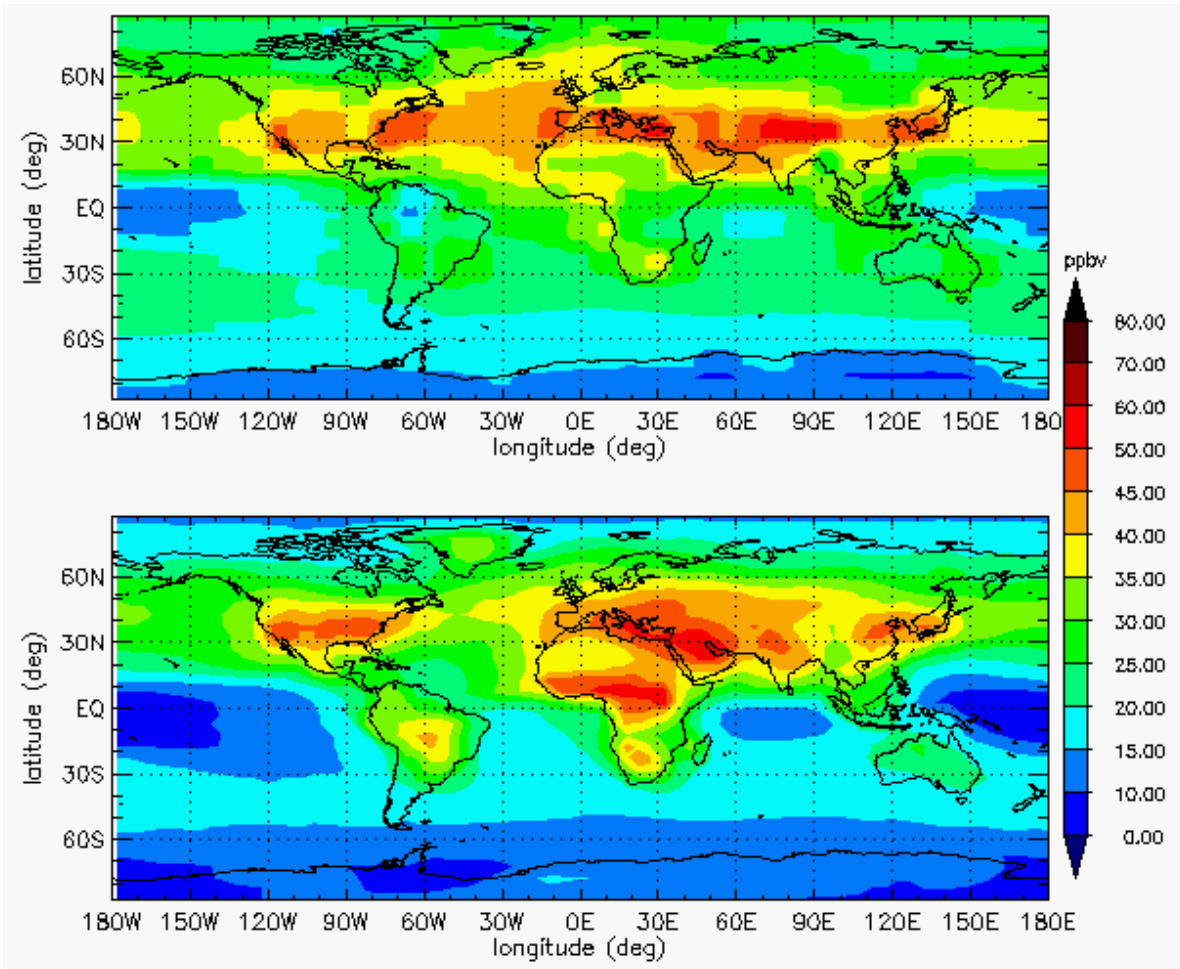

Fig. 10. Calculated decadal average $\mathrm{O}_{3}$ volume mixing ratios [ppbv] at the earth surface for TM3 1990s CLE (upper) and STOCHEM 1990s CLE (lower).

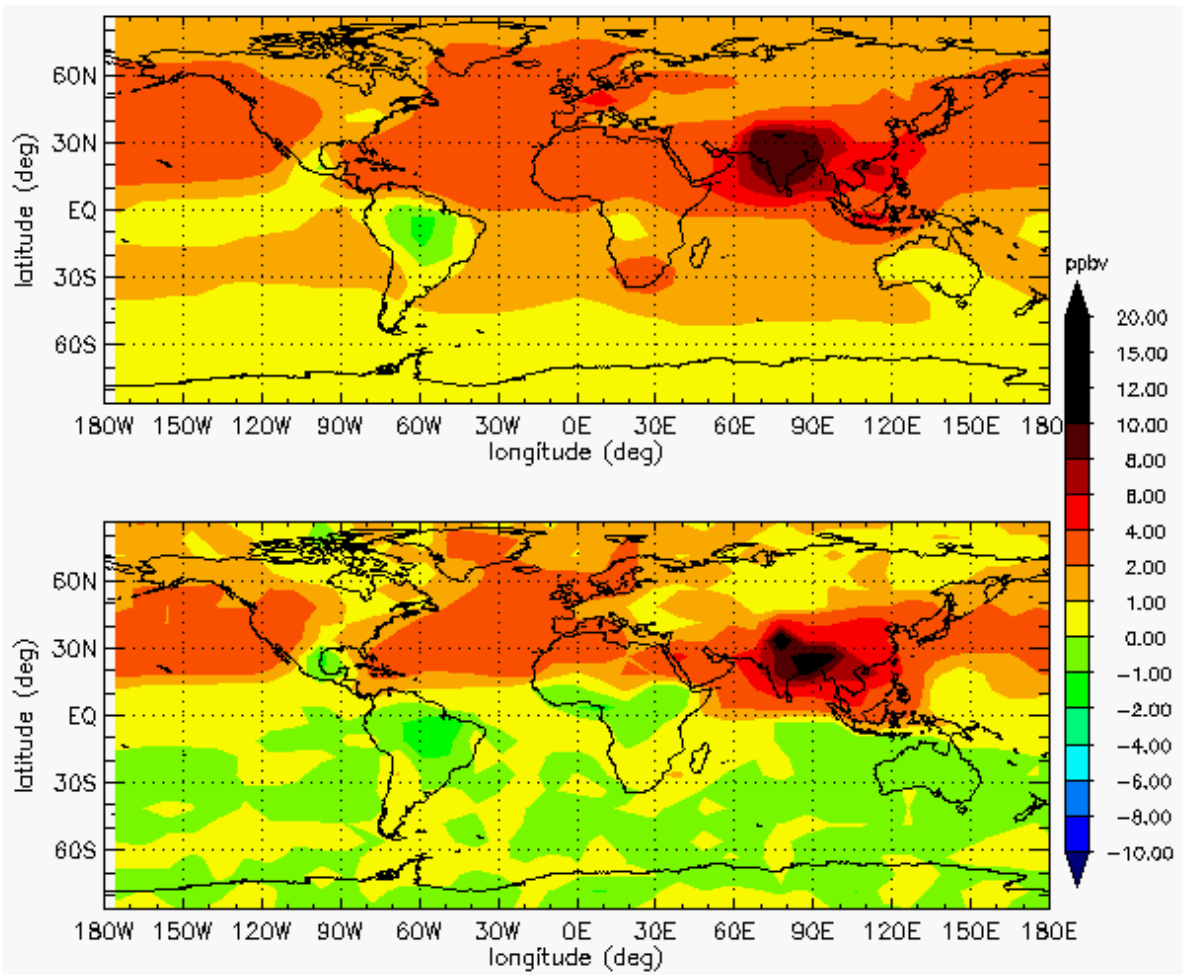

Fig. 11a. Decadal averaged ozone volume mixing ratio differences [ppbv] comparing the 2020s and 1990s for TM3 CLE (upper) and STOCHEM CLE (lower). 


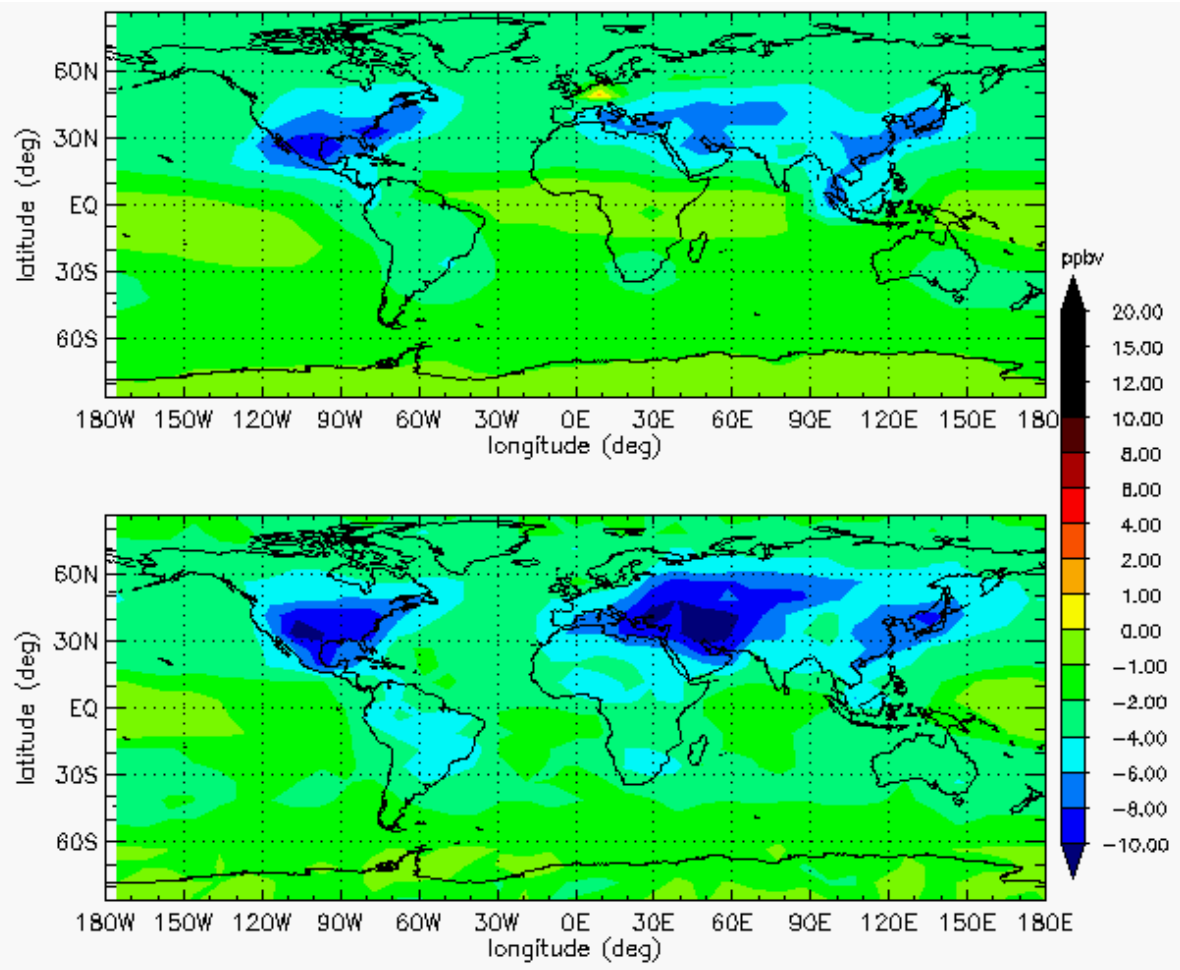

Fig. 11b. Decadal averaged ozone volume mixing ratio differences [ppbv] comparing the 2020s and 1990s for TM3 MFR (upper) and STOCHEM MFR (lower).

The differences of calculated ozone concentrations under the various scenario assumptions during the 2020-2030 and the baseline period 1990-2000 of TM3 and STOCHEM (Fig. 11d) are quite consistent, showing maximum increases of ozone levels between 8-12 ppbv in India, Pakistan and Bangladesh, China and South East Asia. Over the North Pacific and Atlantic Ocean ozone increases by 4-6 ppbv, related to increased background ozone and increases in ship emissions contributing ca. 1 to $1.5 \mathrm{ppbv}$, whereas over the other world latitude bands ozone remains largely unchanged. Interestingly, despite emissions reductions in North America and Europe in the CLE scenario (Fig. 1a and 2), the computed ozone levels in the 2020s do not decrease, but even somewhat increase, clearly illustrating the need for global ozone control strategies. For MFR (Fig. 11b), TM3 calculates ozone decreases of about 5 ppbv over much of the $\mathrm{NH}$, and up to $10 \mathrm{ppbv}$ in the USA, Middle East and South East Asia, comparing the 2020s with the 1990s. A slight increase in ozone is predicted over North and Central Europe, an ozone- $\mathrm{NO}_{\mathrm{x}}$ titration effect, which may be dependent on the coarse model resolution. The STOCHEM model (Fig. 11b) displays a stronger response of surface ozone to emission reductions, with reduced concentrations in large parts of Eastern Europe and Russia. The difference of MFR-pol in the 2020s with CLE in the 2020s (Fig. 11c) shows the effect of $\mathrm{NO}_{\mathrm{x}}, \mathrm{CO}$ and NMVOC reductions (following the MFR scenario) whilst $\mathrm{CH}_{4}$ emissions follow the CLE scenario. It shows that, as expected, the largest effect on ozone of emission reductions stems from air pollutant controls.

We also isolate in Fig. 11c (lower panel) the effect of $\mathrm{CH}_{4}$ abatement, by comparing MFR- $\mathrm{CH}_{4}$ with CLE in the 2020s, showing a uniform ozone reduction by $1-2 \mathrm{ppbv}$ throughout most of the $\mathrm{NH}$ and $\mathrm{SH}$.

It is interesting to observe that the effect of emission reductions is quite linear, e.g. the results of simulation MFR can be largely explained by the combination of MFR- $\mathrm{CH}_{4}$ and MFR-pol. Thus about one third of the $\mathrm{O}_{3}$ reductions associated with the MFR scenario can be obtained by $\mathrm{CH}_{4}$ emission reductions!

\section{Radiative forcing}

The traditional air pollutants $\mathrm{NO}_{\mathrm{x}}, \mathrm{CO}$, and NMVOC as well as the greenhouse gas methane do not only contribute to tropospheric ozone but also have direct (in the case of methane) and indirect (via ozone formation) impacts on radiative forcing. In the CLE scenario methane concentrations continue to increase from $1750 \mathrm{ppbv}$ to about 2090 $2200 \mathrm{ppbv}$ in 2030, whereas in the MFR scenario, methane concentrations in the atmosphere would approximately stabilize in 2030 at $1750 \mathrm{ppbv}$, which corresponds to methane levels in the year 2000. We calculated the radiative forcing of 


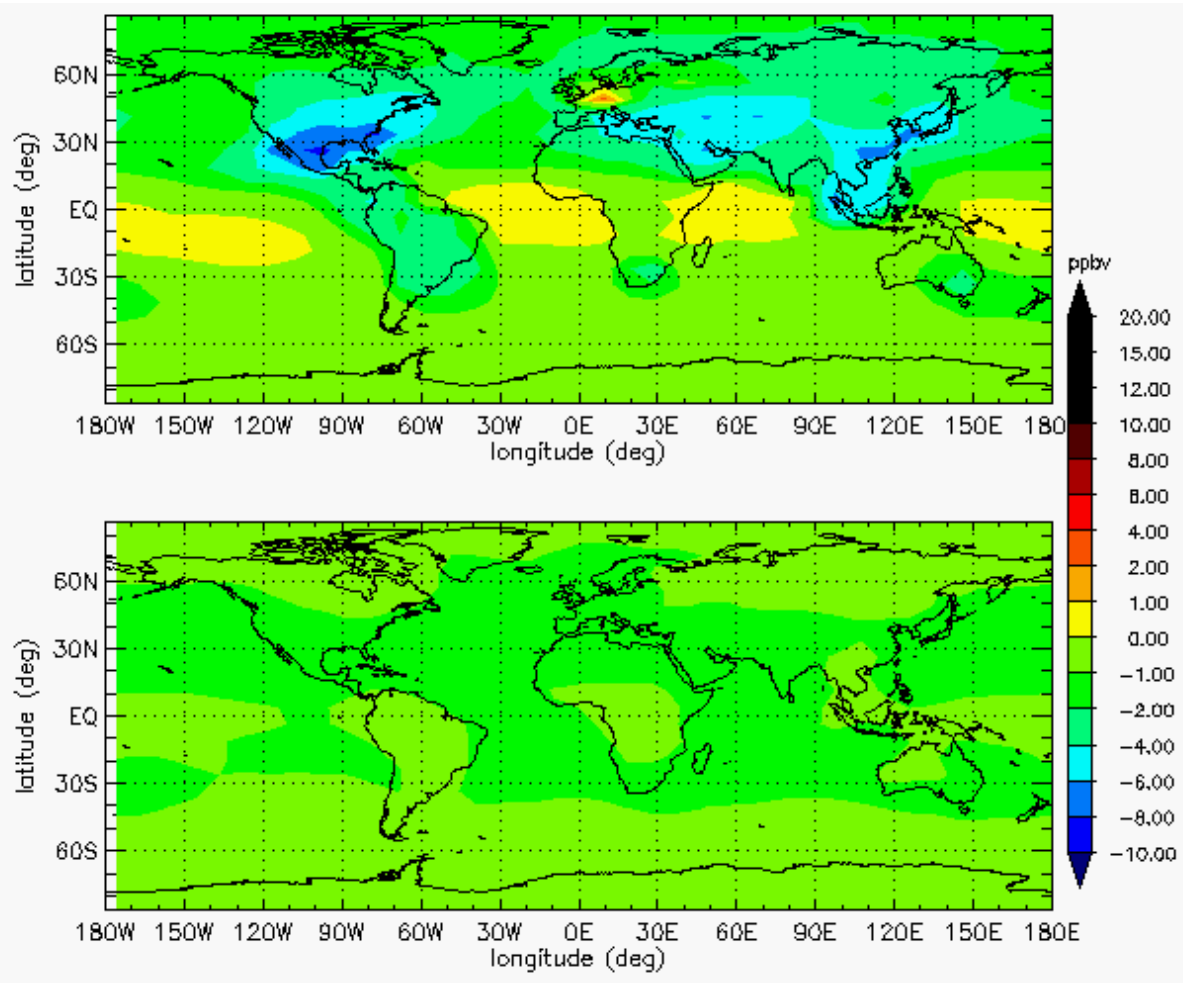

Fig. 11c. Decadal averaged ozone volume mixing ratio differences [ppbv] comparing the 2020s and 1990s for TM3 MFR-pol (upper) and the difference of MFR-CH $\mathrm{CH}_{4}$ and CLE, comparing the 2020s (lower). This highlights the effects of $\mathrm{CH}_{4}$ emission reductions in the 2020s.

the four emission scenarios, following the method described in Stevenson et al. (1998), using the radiative transfer model of Edwards and Slingo (1996).

These forcings account for stratospheric adjustment, assuming the fixed dynamical heating approximation, which reduces instantaneous forcings by $\sim 22 \%$.

In the CLE scenario (Fig. 12), ozone forcing maximizes in the subtropics, and over bright, high albedo surfaces. Peak values of $0.3 \mathrm{Wm}^{-2}$ are found over India and the Arabian Peninsula, coinciding with elevated surface and free tropospheric concentrations. In contrast, the radiative forcings associated with MFR are similar in magnitude ( 0 to $\left.-0.2 \mathrm{Wm}^{-2}\right)$ and distribution, but opposite in sign (Fig. 12b). The global and yearly average forcing of $\mathrm{O}_{3}$ ranges between 0.075 and $-0.072 \mathrm{Wm}^{-2}$ for CLE and MFR, respectively (Table 3).

Radiative forcing between the 2030s and 1990s, calculated for the ozone fields of the STOCHEM model 9 $\left(0.041 \mathrm{Wm}^{-2}\right)$ is only $55 \%$ of the forcing computed for the TM3 ozone results $\left(0.075 \mathrm{Wm}^{-2}\right)$. The difference can be explained partly by the fact that TM3 is somewhat more efficiently producing free tropospheric $\mathrm{O}_{3}$ than STOCHEM. We also note that STOCHEM results display some inter-annual variability in tropopause height, which cannot be completely masked out when comparing the decadal forcings calculated for the 1990s and the 2020s, and which influence signifi- cantly the STOCHEM results. In this respect, TM3 results reflect more accurately the changes arising solely from the emissions changes, as these model runs include no climate variability.

Methane radiative forcing was calculated using the equation presented in Chapter 6 of the IPCC Third Assessment Report (Ramaswamy et al., 2001). Again we compare the forcings for the 2020s relative to those in the 1990s. The $\mathrm{CH}_{4}$ forcings for TM3 results are between $0.17 \mathrm{Wm}^{-2}$ for the CLE case and $0.00 \mathrm{Wm}^{-2}$ for MFR, and 0.13 and $0.00 \mathrm{Wm}^{-2}$ for the STOCHEM results. The lower STOCHEM forcings are caused by somewhat higher STOCHEM OH trends and correspondingly lower $\mathrm{CH}_{4}$ burdens.

As discussed above, in the CLE scenario anthropogenic $\mathrm{CH}_{4}$ emissions increase from $340 \mathrm{Tg} \mathrm{CH}_{4} \mathrm{yr}^{-1}$ in the year 2000 to $450 \mathrm{Tg} \mathrm{CH}_{4} \mathrm{yr}^{-1}$ in 2030. A similar emission increase is given in IPCC TAR for the B2 emission scenario. The corresponding IPCC TAR increase in radiative forcing by $0.06-0.16 \mathrm{Wm}^{-2}$ by the year 2030 relative to the year 2000 (approximately $0.60 \mathrm{Wm}^{-2}$ in 2030 , and $0.49 \mathrm{Wm}^{-2}$ in 2000, relative to pre-industrial levels) compares well with our calculations.

Taking $\mathrm{O}_{3}$ and $\mathrm{CH}_{4}$ radiative forcing together, our models suggest an increase of the global mean radiative forcing between 0.17 and $0.24 \mathrm{Wm}^{-2}$ between the 1990s and the 
Table 3. Radiative Forcings calculated by TM3 and STOCHEM comparing the 2020s with the 1990s.

\begin{tabular}{lllll}
\hline & $\mathrm{O}_{3}$ & $\mathrm{CH}_{4}$ & $\mathrm{CH}_{4}+\mathrm{O}_{3}$ & Relative to TM3 CLE \\
\hline CLE TM3 & 0.075 & 0.167 & 0.242 & 0. \\
CLE STOCHEM & 0.041 & 0.125 & 0.166 & -0.076 \\
MFR TM3 & -0.073 & 0.004 & -0.069 & -0.311 \\
MFR STOCHEM & -0.072 & 0.003 & -0.069 & -0.311 \\
MFR-CH $_{4}$ & 0.029 & -0.039 & -0.010 & -0.252 \\
MFR-pol & -0.030 & 0.221 & 0.191 & -0.051 \\
IPCC-TAR B1-A1FI 2000-2030 & 0.08 to 0.31 & 0.06 to 0.16 & 0.14 to 0.47 & $\mathrm{Nd}$ \\
\hline
\end{tabular}

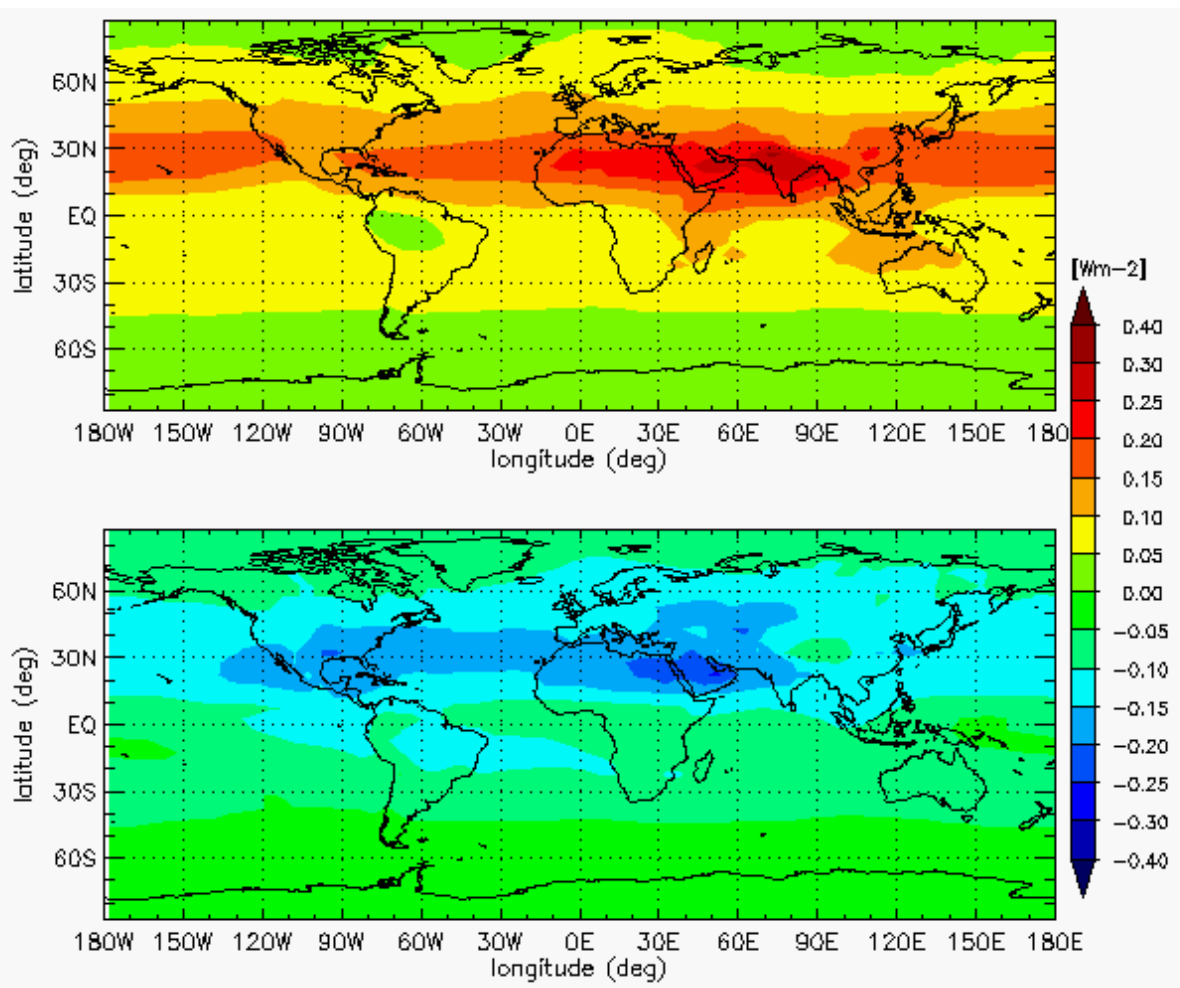

Fig. 12. Annual average radiative forcing $\left[\mathrm{Wm}^{-2}\right]$ of $\mathrm{O}_{3}$ calculated by TM3 comparing the 1990s with the 2020s CLE (upper) and MFR (lower).

2020s, which corresponds to the lower end of the range for the sum of ozone and methane forcing $\left(0.14-0.47 \mathrm{Wm}^{-2}\right)$ presented by IPCC-TAR for the 2000-2030 period (Table 3). It should be noted that the radiative forcing from ozone is not uniformly distributed over the globe, and, as for aerosols, we expect regional climate impacts resulting from regional forcings. Compared to the current legislation (CLE) situation in the 2020s and based on TM3 calculations, maximum reduction of all four emissions (MFR) would reduce the additional radiative forcing from ozone by $0.148 \mathrm{Wm}^{-2}$ and from methane by $0.163 \mathrm{Wm}^{-2}$, i.e., in total by $0.311 \mathrm{Wm}^{-2}$, or by $0.069(=0.311-0.242) \mathrm{Wm}^{-2}$ if compared to the 1990s. For comparison, the radiative forcing from increased $\mathrm{CO}_{2}$ emis- sions alone corresponding to the SRES scenarios is estimated for the period 2000-2030 at $0.8-1.1 \mathrm{Wm}^{-2}$ (IPCC, 2001).

Just controlling methane (MFR- $\mathrm{CH}_{4}$ ) would reduce the direct forcing from methane by $0.206 \mathrm{Wm}^{-2}$ and through the associated reductions in tropospheric ozone by an additional $0.046 \mathrm{Wm}^{-2}$. Conversely, if the air pollutants were reduced but methane emissions remained at current legislation level, the reduced forcing from the ozone reduction $\left(-0.105 \mathrm{Wm}^{-2}\right)$ would be counteracted by the increased lifetime of methane (forcing from methane would increase by $0.054 \mathrm{Wm}^{-2}$ ), so that overall forcing would only decline by $0.051 \mathrm{Wm}^{-2}$. 


\section{Discussion}

7.1 Changes in natural and biomass burning emissions and climate

Our study focused on changes in anthropogenic emissions based on two scenarios prepared by IIASA (see Sect. 2 and Appendix). A particularly important improvement of this study would be a further assessment of the role of biomass burning emissions in atmospheric chemistry, both at present as well as in the future. Further it would be valuable to include in future scenario studies a consistent estimate of NMVOC emissions, although an additional sensitivity study did not show large impacts our the coarse resolution TM3 model: running the 2030 CLE case with 2000 NMVOC emissions decreased 2030 surface $\mathrm{O}_{3}$ levels with globally with $0.23 \mathrm{ppbv}$, and in India and China with 1.0 to $1.5 \mathrm{ppbv}$. However, larger effects are likely when model resolutions are increased. In our experiments we kept natural emissions like soil and lightning $\mathrm{NO}_{\mathrm{x}}$, and wetland emissions of $\mathrm{CH}_{4}$, constant. However, they may strongly change under changed climatic conditions. In fact one can easily imagine a scenario where the increase of natural $\mathrm{CH}_{4}$ emissions more than compensates for the reduction in anthropogenic emissions (Gedney et al., 2004; Houweling et al., 2000b; Shindell et al., 2004).

In the computations presented in this paper the role of climate change has not been accounted for. We mentioned before that natural emissions may change in a different climate. Likewise, the role of changing climate on calculated concentrations needs further attention, as climate change can strongly influence atmospheric chemistry and transport. In general, the main large-scale effect of changing climatic conditions is through emissions (see Sect. 7.1), temperature and humidity, reducing large scale ozone and $\mathrm{CH}_{4}$ abundances. The resulting feed-back effects on $\mathrm{CH}_{4}, \mathrm{O}_{3}$ and $\mathrm{OH}$ may be of similar order of magnitude as those resulting from a

reduction of $\mathrm{CH}_{4}$ emissions alone (Stevenson et al., 2005). On regional scales, however, changes in circulation patterns and the frequency of synoptic disturbances, may lead to increases of ozone episodes (Granier et al., 2003; Murazaki and Hess, 2005). More work is needed, to assess the impacts of the scenario assumptions when taking into account changes in climate and natural emissions when seeking to avoid dangerous levels of climate change and air pollution.

\subsection{Model results}

With these emission projections we have explored a range of future developments of global surface ozone concentrations and radiative forcings. While we were not able to fully address all relevant uncertainties, we have used two distinctively different chemical transport models to span a range of model responses and distil conclusions shared by both models. Given the very coarse resolution of our global models, which was necessary to perform several transient 30 year simulations, and the very different model set-ups, we do not think that these model-measurement differences are problematic. An especially encouraging feature of our set of model simulations was the rather similar response of the two models to changed emissions.

Our two models agree with each other that for the CLE emission projections tropospheric ozone will further increase. Comparing the decadal average ozone values in the 2020 s with those of the 1990s, annual average ozone increases over the Indian sub-continent, Southern China and South East Asia are of the order 8-12 ppbv. The outstanding ozone increases over India are related to the expected strong increases in energy and transport demand, together with the implementation of the EURO-1 standard for vehicles. Over large parts of the NH surface ozone is calculated to increase by $3-5$ ppbv, in large parts of the USA and Europe offsetting for the effects of local $\mathrm{NO}_{\mathrm{x}}, \mathrm{VOC}$, and $\mathrm{CO}$ emissions reductions. We show in our ACPD paper that NH summer concentrations, roughly corresponding to the growing season, can be 5-10 ppbv higher than the annual average concentrations, both at present and in the future. Without any doubt this will cause further damage to vegetation and human health, for which recent insights indicate that ozone is already harmful at concentrations smaller than $40 \mathrm{ppbv}$ (WHO, 2003).

With our models we also find that full application of all presently available emission control measures (the MFR scenario) could reduce annual mean ozone surface concentrations in most parts of the $\mathrm{NH}$ below the presently experienced concentrations, which according to current scientific understanding should not give rise to significant adverse effects on human health and ecosystems. Also NH summer concentrations do not exceed $50 \mathrm{ppbv}$ in both models.

To further explore this issue, we are currently performing, in the context of the IPCC Fourth Assessment Report, a wider multi-model experiment, further exploring the expected range of surface ozone concentrations, assuming scenarios as described in this paper (Dentener et al., 2005 ${ }^{1}$ ).

\subsection{Need for measurements}

We showed in our study that $\mathrm{CH}_{4}$ emission abatements are a powerful method to decrease the impact on climate and reduce air pollution. However, how are we going to verify if investments in emission reductions are effective? Using the current set of world-wide observations maintained by the NOAA CMDL group partially constrains the emissions from relatively large regions (Bergamaschi et al., 2000a; Dentener et al., 2003b; Houweling et al., 1999). In a very recent inverse model study, Bergamaschi et al. (2004) showed that emission estimates of individual European countries can

\footnotetext{
${ }^{1}$ Dentener F., Stevenson, D., Ellingsen, K., Noije T., et al.: Global Atmospheric Environment for the next Generation, Geophys. Res. Lett., submitted, 2005.
} 
be determined, using a larger dataset of $\mathrm{CH}_{4}$ measurements including high frequency observations at several European and global stations. It is highly desirable to have additional high quality measurements of methane in especially the high emission regions Russia, India and China in the next 2 decades. In the future, satellite measurements, e.g. from SCIAMACHY (Buchwitz et al., 2004), maybe provide further constraints on emissions or emission trends. Likewise, few measurement stations for background ozone are available, and datasets are sometimes of heterogeneous quality. Changes in ozone will have an intercontinental signature, and it is imperative that current high accuracy measurement facilities remain in place to determine these signals. We think that these are good investments considering the high costs of emission controls involved.

\section{Conclusions}

We have performed a series of transient atmospheric chemistry transport model calculations for the period 1990-2030 to assess the synergies and trade-offs of $\mathrm{CH}_{4}$ and $\mathrm{NO}_{\mathrm{x}}, \mathrm{CO}$, NMVOC air pollution control strategies. The two scenarios, the current legislation (CLE) implementing technical measures to prevent air pollution and the MFR (Maximum Technically Feasible Reduction), go beyond the business-as-usual assumptions on emission factors that were made in the IPCC SRES scenarios. We show here the importance of attaining at least the CLE scenario, although we realize that there may a significant lag between legislation and implementation of emission controls in developing countries.

Our calculations highlight important and multiple interactions between the "traditional" air pollutants $\mathrm{NO}_{\mathrm{x}}, \mathrm{VOC}$ and $\mathrm{CO}$, together with methane, which is mainly considered in the context of greenhouse gas reductions. Firstly, methane makes an important contribution to global background ozone. When methane emissions are controlled to the maximum feasible extent (MFR) and the other pollutants emissions are maintained at their CLE levels, ozone levels would be world-wide reduced by 1 to 2 ppbv, partly compensating the increase of typically 5 ppbv that is calculated for the CLE projection. Thus, the cost-effectiveness of hemispheric or global methane controls (as well as their side-benefits on greenhouse gas controls) is worthwhile to analyze when considering the scope of additional $\mathrm{NO}_{\mathrm{x}}$ and VOC controls for further ozone reductions. For example, a recent study (Amann et al., 1999) indicated that in order to comply with anticipated air quality standards for ozone in the year 2010 in Europe alone additional investments in the order of 5 billion Euro per year are needed. Obviously, worldwide these numbers are much higher, showing the economic scope for methane emission reductions to reduce air pollution. A first study on the economic potential of $\mathrm{CH}_{4}$ emission reductions for $\mathrm{O}_{3}$ management (West and Fiore, 2005), indeed shows large - but uncertain - economic benefits related to agricultural losses and human health. To reduce the greenhouse effect, methane emissions reductions for many source categories are likely to be economically more attractive than equivalent amounts of $\mathrm{CO}_{2}$ emission reductions.

Secondly, tropospheric ozone, in addition to its health and vegetation effects, is a potent greenhouse gas. Thus, ozone reductions will not only have benefits for local air quality, but also reduce radiative forcing. In the CLE case, the anticipated changes in emissions will contribute an additional 0.041 to $0.075 \mathrm{Wm}^{-2}$ to the radiative forcing of the conventional greenhouse gases that are considered in the Kyoto protocol. In the most optimistic MFR case, this could be turned into a reduction of $0.073 \mathrm{Wm}^{-2}$. This can be compared to the $0.14-0.47 \mathrm{Wm}^{-2}$ increase of methane and ozone radiative forcings associated with the SRES scenarios. However, isolated reductions of the regional air pollutants $\mathrm{NO}_{\mathrm{x}}, \mathrm{CO}$ and $\mathrm{VOC}$ that lead to lower ozone will increase, via the $\mathrm{OH}$ chemistry, the lifetime of methane and thus counteract greenhouse gas mitigation efforts. While this might sound like a strategic dilemma, it underlines the urgency - and effectiveness - of methane controls. Measures to reduce methane emissions, while having direct beneficial impact on radiative forcing, will in addition balance out negative effects from air pollution control that have negative impacts on the lifetime of methane in the atmosphere.

\section{Appendix}

\subsection{A1 Rains}

RAINS combines national perspectives on sectoral economic developments and emission generating activities with emission factors that describe the technical features of the emission sources, considering their change over time resulting from country- and sector-specific emission control legislation. For this study we used the European (Amann et al., 2004; Klaassen et al., 2004) and Asian (Cofala et al., 2004; Klimont et al., 2001; RAINS-Asia, 2001) implementations of the RAINS model and complemented them with countryspecific data for North America, the countries of the former Soviet Union, Latin America, Africa and Australia. An overview report is available on the internet (Cofala et al., 2005).

\subsection{A2 Projections of activity levels}

The basis of the activity levels in our two scenarios are the present day national perspectives on future sectoral economic developments up to the year 2030. These projections reflect national governmental expectations and ambitions, and underlying assumptions on the development of oil prices. We distinguish fuel consumption for 6 economic sectors and 22 fuel types, 10 vehicle categories, production levels of 20 industrial sectors and livestock numbers for 7 animal categories. We use baseline projections for the 25 European 
Union (EU) countries (EC, 2003), and for the non-EU European countries national projections presented by the European Environment Agency (EEA, 2002). For Russia, the national energy strategy developed by the Russian Ministry of Industry and Energy (MTE, 2003), been introduced into RAINS and extended until 2030 by Popov (2003). Projections for Asia have been extracted from the recent RAINSAsia database (Boudri et al., 2002; Cofala et al., 2004), including information on countries, regions and mega-cities. Especially in India large increases in transport and energy demand are predicted. To derive projections for the other world regions, we adjusted the national energy consumption and industrial production levels as reported by the International Energy Agency (IEA, 2002) and the UN commodity statistics (UN, 2000) for the year 2000 following the trends of future economic and energy development from the IPCC SRES B2 scenario, as calculated with the MESSAGE model (Nakicenovic et al., 2000; Riahi and Roehrl, 2000). Since the official energy statistics of many developing countries do not include total biomass fuel consumption, biomass use data for Latin America and Africa was taken from Riahi and Roehrl (2000).

The activity levels are the same in the MFR and CLE scenarios, and correspond to global $\mathrm{CO}_{2}$ emissions of 6.4 PgC/yr in 2000, and $10.8 \mathrm{Pg} \mathrm{C} / \mathrm{yr}$ in 2030 . The increase between 2000-2030 is consistent with other SRES-B2 scenario models.

\subsection{A3 Present and future emission factors}

Present day $\mathrm{NO}_{\mathrm{x}}$ emission factors, distinguishing the removal efficiencies of individual control technologies, have been taken from the RAINS database (Cofala et al., 2000; Cofala and Syri, 1998). For Europe, North America, Russia and Southeast Asia, we used country-specific emission factors that reflect the national characteristics of the emission sources (e.g., fuel quality, fleet composition, maintenance levels), and we applied default factors for the other countries.

$\mathrm{CO}$ emission factors were derived from the IPCC guidelines (IPCC, 1997). In addition, some factors (e.g. wood burning in the domestic sector, US-specific factors for mobile sources) were taken from the USA emission trends report (EPA, 2001). Important parameters determining emissions from coal burning (e.g., calorific value, existing emission control equipment, etc.) are provided in the IEA Coal Research directory of world coal fired power plants (IEA, 1997).

$\mathrm{CH}_{4}$ emission factors have been compiled from the literature using IPCC recommended emission factors (IPCC, 1997) as a starting point, and adapted to country-specific circumstances (Höglund-Isaksson and Mechler, 2004; Mechler, 2003).

For the future evolution of emission factors, we consider the technical features of the most important emission control technologies that are presently available and contained in the
RAINS database. Using this information, we consider for the CLE scenario the country-, sector- and technology-specific impacts of emission control measures that are imposed by present (2002) legislation in Europe and N. America. In addition, we assume for European countries compliance with the 2010 emission ceilings established in the Emission Ceilings Directive of the EU and the Gothenburg Protocol of the Convention on Long-range Trans-boundary Air Pollution $\left(\mathrm{NO}_{\mathrm{x}}\right.$, $\mathrm{VOC}, \mathrm{SO}_{2}, \mathrm{NH}_{3}$ ).

While there is well-documented information for most industrialized countries available, information for many developing countries is sparse. However, a wealth of relevant information on new legislation became recently available, especially on legislation for the transport sector in Asia and Latin America (Bertelsen and Walsh, 2000; Weaver and Walsh, 1996), see also http://www.cleanairnet.org/cai/1403/ channel.html. Country-specific information for South-east Asia was collected in the context of the RAINS-Asia II project (Boudri et al., 2002; RAINS-Asia, 2001) and updated with recent information on mobile sources from the clean Air initiative from the World Bank. For other countries and world regions, information for stationary sources was taken from the emission standards handbook (McConville, 1997).

In addition to the CLE scenario, we estimated the theoretical scope for emission controls offered by full application of all presently available technical emission control measures: the "maximum technically feasible reduction" or MFR scenario. We did not take account for practical limitations on the penetration of these most advanced emission control measures imposed by the gradual turnover of existing capital stock, and we did not estimate the obviously high costs of such a theoretical emission control strategy. On the other hand, we did not consider in this scenario the potential for emission reductions offered by structural changes, such as increased energy efficiency measures, fuel substitution, more efficient production technologies or reduced transport demand. Earlier studies have shown that the emission reduction potential of such measures is considerable and that some of the measures could be implemented in a cost-effective manner (Rentz et al., 1994; Van Vuuren et al., 2005).

\subsection{A4 Comparison of emissions with other studies}

For $\mathrm{NO}_{\mathrm{x}}$, resulting emission estimates for the year 2000 for most industrialized countries do not differ by more than 5$10 \%$ from national inventories, although there are somewhat larger differences to inventories for some developing countries published by different sources, e.g. the EDGAR3.2 emissions reference database (Olivier and Berdowski, 2001). Our estimates are also consistent with the SRES estimates for the year 2000 which were $6 \%$ higher than our assessment. However, global $\mathrm{NO}_{\mathrm{x}}$ emissions are calculated to increase until 2030 by only $13 \%$ in the CLE scenario. This estimated increase is significantly lower than projections from earlier studies, including the global emission scenarios published in 
the IPCC SRES report (Nakicenovic et al., 2000). In contrast for 2030 the SRES scenarios suggest global anthropogenic $\mathrm{NO}_{\mathrm{x}}$ to increase between 65\% (SRES-B2) and 90\% (SRESA2). With comparable rates of growth in the vehicle stock, the difference can be explained by the fact that the SRES scenarios did not include recently introduced air pollution control legislation in developing countries. This refers first of all to legislation on mobile sources (catalytic converters, engine modifications), which became mandatory in many countries in Asia, Latin America, Eastern Europe and Russia. Further, the SRES simulations for the OECD countries include air

pollution control measures as in force in mid-1990's, without assuming further changes. In our scenarios we included recently decided stricter legislation in Europe (e.g., EURO IV/V standards on cars and trucks, Large Combustion Plant Directive, IPPC Directive for industrial sources), as well as current reduction plans in North America. Without inclusion of those control measures (both in the OECD and in the developing countries) the 2030 emissions would have been $50 \%$ higher than 2000 emissions. Approximately half of this difference results from implementation of controls in the developing world and reforming economies, and the balance is due to phasing-in more stringent measures in the OECD countries. The remaining difference to the marker B2 scenario (MESSAGE) can be explained by different assumptions about activity levels. In our MFR scenario we explored the scope for reduced global emissions offered by full application of today's most advanced emission control techniques. Although rather costly, global $\mathrm{NO}_{\mathrm{x}}$ emissions could be reduced in 2030 compared to CLE by $67 \%$ compared to the year 2000.

For CO, the RAINS emission estimate of the total world anthropogenic emissions (without biomass burning) are 9\% lower than those of EDGAR3.2, which is mainly due to lower RAINS emissions in Europe (different assumptions on the effect of catalytic converters on the emissions of mobile sources), and Asia and Russia (lower emission factors from coal and wood burning in small stoves). Also on a regional (e.g. Europe, Africa) level the RAINS emissions in the year 2000 are consistent with other estimates (e.g. EDGAR3.2 and SRES). We predict that emission controls for vehicles and a switch from coal and fuel-wood to cleaner fuels in the residential sector decrease $\mathrm{CO}$ emissions in most world regions, so that global CO emissions decrease by $16 \%$ from the year 2000 to 2030 . Without these presently decided pollution control measures for vehicles, global $\mathrm{CO}$ emissions would grow in our calculations by approximately $45 \%$ up to 2030 , which is close to the lower range (e.g. B1) in the SRES scenarios. Assuming the MFR scenario, ussing available technology anthropogenic $\mathrm{CO}$ emissions can be reduced by $53 \%$ in 2030 ,

Compared to 2000 , methane emissions, assuming implementation of present emission control technology, are computed to increase by $35 \%$ up to 2030 ; in agreement with the range of emissions spanned by the SRES scenarios. Differ- ences between our present day $\mathrm{CH}_{4}$ emission estimates and country data reported to UNFCCC (http://unfccc.int) are typically in the range of $\pm 10 \%$ to $30 \%$. Note, however, that for many countries the UNFCCC estimates are missing, inaccurate or incomplete, making a direct comparison difficult. Methane emissions under MFR decrease by 5\% compared to 2000; and by $25 \%$ compared to CLE 2030.

All in all, the range of $\mathrm{CH}_{4}$ emissions increases under CLE and MFR is quite consistent with the IPCC SRES scenarios. Interestingly, analysis of our model calculations showed that in case of methane, the results obtained with the MFR scenario better explain the recently observed stabilization of atmospheric $\mathrm{CH}_{4}$ concentrations.

The global $\mathrm{NO}_{\mathrm{x}}, \mathrm{CO}$, and NMVOC emissions, however, are distinctly dissimilar from the SRES scenarios.

Acknowledgements. We thank NOAA CMDL for making their data continuously available through the internet. All contributors to World Data Centre for surface ozone are gratefully acknowledged.

E. Brunke (CSIRO) provided additional surface ozone data for Cape Point and Mace Head. DS thanks the Environment Agency (P4-F02) and NERC (NER/J/S/2000/00840) for fellowship funding, and UGAMP for supercomputing resources. RGD thanks DEFRA for support under contract CPEA/7. FD and MA thank the network of excellence ACCENT for support. Finally we are grateful for the hard work and detailed comments of the two anonymous referees which greatly improved the manuscript.

Edited by: Y. Balkanski

\section{References}

Akimoto, H.: Global Air Quality and Pollution, Science, 302, 17171719, 2003.

Amann, M., Bertok, I., Cofala, J., Gyarfas, F., Heyes, C., Klimont, Z., Makowski, M., Schöpp, W., and Syri, S.: Cost-effective Control of Acidification and Ground-Level Ozone - Seventh Interim Report, International Institute for Applied Systems Analysis, Laxenburg, Austria, pp. 1-87,1999.

Amann, M., Cofala, J., Heyes, C., Klimont, Z., Mechler, R., Posch, M., and Schoepp, W.: The RAINS model. Documentation of the model approach prepared for the RAINS peer review 2004, (http: //www.iiasa.ac.at/rains/review/review-full.pdf), International Institute for Applied Systems Analysis (IIASA), Laxenburg, Austria, pp. 1-156, 2004.

Andreae, M. O. and Merlot, P.: Emission of trace gases and aerosols from biomass burning, Global Biogeochem. Cycles, 15, 955966, 2001.

Arellano Jr., A. F., Kasibhatla, P. S., Giglio, L., van der Werf, G. R., and Randerson, J. T.: Top-down estimates of global CO sources using MOPITT measurements, Geophys. Res. Lett., 31, L01104, doi:10.1029/2003GL018609, 2004.

Bergamaschi, P., Bräunlich, M., Marik, T., and Brenninkmeijer, C. A. M.: Measurements of the carbon and hydrogen isotopes of atmospheric methane at Izana, Tenerife: Seasonal cycles and synoptic-scale variations, J. Geophys. Res., 105 (D11), 14 53114546, 2000a. 
Bergamaschi, P., Hein, R., Brenninkmeijer, C. A. M., and Crutzen, P. J.: Inverse modeling of the global CO cycle 1. Inversion of CO mixing ratios, J. Geophys. Res., 105, 1909-1927, 2000b.

Bergamaschi, P., Krol, M., Dentener, F., Vermeulen, A., Meinhardt, F., Graul, R., Ramonet, M., Peters, W., and Dlugokencky, E. J.: Inverse modelling of national and European $\mathrm{CH}_{4}$ emissions using the atmospheric zoom model TM5, Atmos. Chem. Phys. Discuss., 5, 1007-1066, 2005,

SRef-ID: 1680-7375/acpd/2005-5-1007.

Bertelsen, B., and Walsh, M. P.: Motor Vehicle Emissions and the Government. Car Lines, (www.walshcarlines.com), Arlington, USA, 2000.

Boudri, J. C., Hordijk, L., Kroeze, C., Amann, M., Cofala, J., Bertok, I., Junfeng, L., Lin, D., Shuang, Z., Runquing, H., Panwar, T. S., Gupta, S.,Singh, D., Kumar,A., Vipradas, M. C., Dadhich, P., Prasad, N. S., and Srivastava, L: The potential contribution of renewable energy in air pollution abatement in China and India, Energy Policy, 30, 409-424, 2002.

Buchwitz, R., deBeek, R., Burrows, J. P., Bovensmann, H., Warneke, T., Notholt, J., Meirink, J. F., Goede, A. P. H., Bergamaschi, P., Körner, S., Heimann, M., Muller, J. F., and Schulz, A.: Atmospheric methane and carbon dioxide from SCIAMACHY satellite data: initial comparison with chemistry and transport models, Atmos. Chem. Phys., 5, 941-962, 2005,

SRef-ID: 1680-7324/acp/2005-5-941.

Buse, A., Mill, G.,Harmens,H., Buker, P., Hayes, F., Williams,P., Emberson,L., Cinderby, S., Ashmore, M., Holland, M., and De Temmerman, L.: Air Pollution and Vegetation, UNECE ICP Vegetation, Bangor, UK. http://icpvegetation.ceh.ac.uk/annual_ report_2003_pdf.htm, 2003.

Butler, T., Simmonds, I., and Rayner, P.: Mass balance inverse modelling of methane in the 1990s using a Chemistry Transport Model, Atmos. Chem. Phys., 4, 2561-2580, 2004,

SRef-ID: 1680-7324/acp/2004-4-2561.

Cifuentes, L., Broja-Aburto, V. H., Gouveia, N., Thurston, G., and David, D. L.: Hidden health benefits of greenhouse gas mitigation, Science, 293, 1258-1259, 2001.

Cofala, J., Amann, M. Gyarfas,F., Schöpp,W., Boudri, J. C., Hordijk, L., Kroeze, C., Junfeng, J., Lin, D., Panwar, T. S., and Gupta, S.: Cost-effective Control of $\mathrm{CO}_{2}$ Emissions in Asia, Journal of Environmental Management, 72, 149-161, 2004.

Cofala, J., Amann, M., and Klimont, Z.: Calculating Emission Control Scenarios and their Costs in the RAINS Model: Current Experience and Future Needs, Pollution Atmospherique, October 2000, 37-48, 2000.

Cofala, J., Amann, M., Klimont, Z., and Schöpp, W.: Scenarios of World Anthropogenic Emissions of $\mathrm{SO}_{2}, \mathrm{NO}_{\mathrm{x}}$, and $\mathrm{CO}$ up to 2030, in Internal report of the Transboundary Air Pollution Programme, pp. 17, http://www.iiasa.ac.at/rains/global_emiss/ global_emiss.html, International Institute for Applied Systems Analysis, Laxenburg, Austria, 2005.

Cofala, J. and Syri, S.: Nitrogen oxides emissions, abatement technologies and related costs for Europe in the RAINS model database, International Institute for Applied Systems Analysis, Laxenburg, Austria, 1998.

Collins, W. J., Stevenson, D. S., Johnson, C. E., and Derwent, R. G.: The role of convection in determining the budget of odd hydrogen in the upper troposphere, J. Geophys. Res., 104 (D21), 26927-26941, 1999.
Collins, W. J., Stevenson, D. S., Johnson, C. E., and Derwent, R. G.: Tropospheric ozone in a global-scale three-dimensional Lagrangian model and its response to NOx emission controls, J. Atmos. Chem., 26, 223-274, 1997.

Collins, W. J., Derwent, R. G., Johnson, C. E., and Stevenson, D. S.: A comparison of two schemes for the convective transport of chemical species in a Lagrangian global chemistry model, Q.J.R. Meteorol.Soc., 128, 991-1009, 2002.

Crutzen, P. J.: Photochemical reactions initiated by and influencing ozone in unpolluted tropospheric air, Tellus, 26, 46-57, 1974.

Dentener, F., Stevenson, D., Cofala, J., Mechler, R., Amann, M., Bergamaschi, P., Raes, F., and Derwent, R.: The impact of air pollutant and methane emission controls on tropospheric ozone and radiative forcing: CTM calculations for the period 1990 2030, Atmos. Chem. Phys. Discuss., 4, 8471-8538, 2004, SRef-ID: 1680-7375/acpd/2004-4-8471.

Dentener, F., Feichter, J., and Jeuken,A.: Simulation of the transport of $\mathrm{Rn}^{222}$ using on-line and off-line global models at different horizontal resolutions: a detailed comparison with measurements, Tellus, 51B, 573-602, 1999.

Dentener, F., Peters, W., Krol, M., van Weele, M., Bergamaschi, P., and Lelieveld, J.: Inter-annual-variability and trend of $\mathrm{CH}_{4}$ lifetime as a measure for $\mathrm{OH}$ changes in the 1979-1993 time period, J. Geophys. Res., 108 (D15), 4442 doi:10.1029/2002JD002916, 2003a.

Dentener, F., van Weele, M., Krol, M., Houweling, S., and van Velthoven, P.: Trends and inter-annual variability of methane emissions derived from 1979-1993 global CTM simulations, Atmos. Chem. Phys., 3, 73-88, 2003b,

SRef-ID: 1680-7324/acp/2003-3-73

Dlugokencky, E. J., Dutton, E. G., Novelli, P. C., and Masarie, K. A.: Changes in $\mathrm{CH}_{4}$ and $\mathrm{CO}$ growth rates after the eruption of Mt. Pinatubo and their link with changes in tropical tropospheric UV flux, Geophys. Res. Lett., 23, 2761-2764, 1996.

Dlugokencky, E. J., Houweling, S., Bruhwiler, L., Masarie, K. A., Lang, P. M., Miller, J. B., and Tans, P. P: Atmospheric methane levels off: Temporary pause or a new steady-state?, Geophys. Res. Lett., 30 (19), 1992, doi:10.1029/2003GL018126, 2003.

Duncan, B. N., Martin, R. V., Staudt, A. C., Yevich, R., and Logan, J. A. J.: Interannual and seasonal variability of biomass burning emissions constrained by satellite observations, J. Geophys. Res., 108, ACH1, doi:10.1029/2002JD002378, 2003.

EC: European Energy and Transport - Trends to 2030: European commission, DG TREN, (http://europa.eu.int/comm/ dgs/energy_transport/figures/trends_2030/index_en.htm), European Commission, Brussels, Belgium, 2003.

Edwards, J. M. and Slingo, A.: Studies with a flexible new radiation code. I: Choosing a configuration for a large-scale model, Q.J.R. Meteorol.Soc., 122, 678-719, 1996.

EEA: The SHAIR scenario: Towards air and climate change outlooks, integrated assessment methodologies and tools applied to air pollution and greenhouse gases. Topic report 12/2001, European Environment Agency, Copenhagen, Denmark, 2002.

EPA: U.S. Methane Emissions 1990-2020: Inventories, Projections, and Opportunities for Reductions, United States Environmental Protection Agency, Washington D.C., USA, 1999.

EPA: National Air Quality and Emissions Trends Report, 1999, US EPA report 454/R-01-004, Office of Air Quality, Planning and Standards, Research (http://www.epa.gov/air/aqtrnd99/ 
pdfs), Triangle Park, USA, 2001.

Fiore, A. M., Jacob, D. J., Field, B. D., Streets, D. G., Fernandes, S. D., and Jang, C.: Linking ozone pollution and climate change: The case for controlling methane, Geophys. Res. Lett, 29 (19), 25-1/25-4, doi:10.1029/2002GL015601, 2002.

Ganzeveld, L., Lelieveld, J., and Roelofs, G.-J.: A dry deposition parameterization for sulfur oxides in a chemistry and general circulation model, J. Geophys. Res., 103, 5679-5694, 1998.

Gedney, N., Cox, P. M., and Huntingford, C.: Climate feedback from wetland methane emissions, Geophys. Res. Lett., 31, L20503, doi:10.1029/2004GL020919, 2004.

Gery, M. W., Whitten, G. Z., Killus, J. P., and Dodge, M. C.: A photochemical kinetics mechanism for urban and regional scale computer modeling, J. Geophys. Res., 94, 12 925-12 956, 1989.

Gibson, R., Kallberg, P., and Uppsala, S.: The ECMWF re-analysis (ERA) project, ECMWF Newsletter, p. 7-17, European Centre for Medium Range Weather Forecasts, Reading, England, 1997.

Granier, C., Balkanski, Y., Bekki, S., Bey, I., Collins, W., Dentener, F., Ganzeveld, L., Houweling, S., Muller, J. F., Olivier, J., Sander, R., Sanderson, M., Schultz, M., Sciare, J., Stevenson, D., Sturges, W., and Zerefos, C.: Impact of climate change on Tropospheric ozone, edited by: Isaksen, I. S. A., DG Research, European Commision, EUR report 20623, Brussels, 2003.

Guelle, W., Balkanski, Y. J., Schultz, M., Dulac, F., and Monfray, P.: Wet deposition in a global size-dependent aerosol transport model, 1 . Comparison with 1 year ${ }^{210} \mathrm{~Pb}$ simulation with ground measurements, J. Geophys. Res., 103, 11 429-11 445, 1998.

Hansen, J., Sato, M., Ruedy, R., Lacis, A., and Oinas, V.: Global warming in the twenty-first century: An alternative scenario, Proc. Natl. Acad. Sci., 97, 9875-9880, doi:10.1073/pnas170278997, 2000.

He, K., Huo, H., and Zhang, Q.: Urban Air pollution in China: Current Status Characteristics, and Progress, Ann. Rev. Energy Environ., 27, 397-431, 2002.

Hendriks, C. A., De Jaeger, D., and Blok, K.: Emission Reduction Potential and Costs for Methane and Nitrous Oxide in the EU-15, ECOFYS, Utrecht, The Netherlands, 1998.

Hertel, O., Berkowicz, R., Christensen, J., and Hov, O.: Test of two numerical schemes for use in atmospheric transport-chemistry models, Atmos. Environ., 27, 2591-2611, 1993.

Höglund-Isaksson, L. and Mechler, R.: The GAINS Model for Greenhouse Gases: Methane. IR-078, International Institute for Applied Systems Analysis, Laxenburg, Austria, 2004.

Houweling, S., Dentener, F., and Lelieveld, J.: The impact of nonmethane hydrocarbon compounds on tropospheric photochemistry, J. Geophys. Res., 103 (D9), 10 673-10 696, 1998.

Houweling, S., Dentener, F., Lelieveld, J., Walter, B., and Dlugokencky, E.: The modeling of tropospheric methane: How well can point measurements be reproduced by a global model?, J. Geophys. Res., 105 (D7), 8981-9002, 2000a.

Houweling, S., Dentener, F. J., and Lelieveld, J.: Simulation of preindustrial atmospheric methane to contrain the global source strength of natural wetlands, J. Geophys. Res., 105, 17243$17255,2000 b$.

Houweling, S., Kaminski, T., Dentener, F. J., Lelieveld, J., and Heimann, M.: Inverse modeling of methane sources and sinks using the adjoint of a global transport model, J. Geophys. Res., 104, 26 137-26 160, 1999.

IEA, CR: Coal Power 2: World coal-fired power stations and their pollution control systems., IEA Coal Research, International Energy Agency, London, UK, 1997.

IEA: Energy Statistics and Balances - OECD and Non-OECD Countries (CD-ROMs), International Energy Agency, IParis, France, 2002.

IPCC: Revised 1996 IPCC Guidelines for National Greenhouse Gas Inventories, IPCC WG1, Technical Support Unit, Bracknell, England, 1997.

IPCC: Climate Change 2001: The scientific basis, in: Contribution of working group I to the Third assessment report of the Intergovernmental Panel on Climate, edited by: Houghton, J. T., Ding, Y., Griggs, D. J., Noguer, M., v.d. Linden, P. J., Dai, X., Maskell, K., and Johnson, C. A., Cambridge University Press, Cambridge, United Kingdom and New York, USA, 2001.

Isaksen, I., Jackman, C. H., Baughcum, S., Dentener, F. Grose, W., Kasibhatla, P., Kinnison, D., Ko, M., McDonnel, M., Pitari, G., and Wubbles, D.: Modeling the Chemical Composition of the Future Atmosphere, in: IPCC, Aviation and the global Atmosphere, edited by: Penner, J., Lister, D., Griggs, D. J., Dokken, D., and McFarland, M., pp. 121-164, Cambridge University Press, Cambridge, UK, 1999.

Isaksen, I. S. A. and Hov, O.: Calculations of trends in the tropospheric concentrations of $\mathrm{O}_{3}, \mathrm{OH}, \mathrm{CO}, \mathrm{CH}_{4}$ and $\mathrm{NO}_{\mathrm{x}}$, Tellus, 39B, 271-283, 1987.

Jeuken, A., Veefkind, P., Dentener, F., Metzger, S., and RoblesGonzalez, C.: Simulation of the aerosol optical depth over Europe for August 1997 and a comparison with observations, J. Geophys. Res., 106, 28 295-28 311, 2001.

Klaassen, G., Amann, M., Berglund, C., Cofala, J., HoeglundIsaksson, L., Heyes, C., Mechler, R., Tohka, A., Schoepp, W., and Winiwarter, W.: The extension of the RAINS model to greenhouse gases, pp. 136, IR-04-015, International Institute for Applied System Analysis, Laxenburg, 2004.

Klimont, K., Cofala, J., Schoepp, W., Amann, M., Streets, D. G., Ichikawa, Y., and Fujita, S.: Projections of $\mathrm{SO}_{2}, \mathrm{NO}_{\mathrm{x}}, \mathrm{NH}_{3}$, and VOC Emissions in East Asia up to 2030, Water, Air, and Soil Pollution, 130, 193-198, 2001.

Krol, M. and Weele, M. V.: Implications of variation of photodissociation rates for global atmospheric chemistry, Atmos. Env., 31, 1257-1273, 1997.

Lelieveld, J. and Dentener, F. J.: What controls tropospheric ozone?, J. Geophys. Res., 105, 3531-3551, 2000.

Li, D. and Shine, K. P.: A 4-dimensional ozone climatology for UGAMP models, UGAMP internal report, University of Reading, UK, Reading, 1995.

Logan, J. A.: An analysis of ozonesonde data for the troposphere: Recommendations for testing 3-D models, and development of a gridded climatology for tropospheric ozone, J. Geophys. Res., 104, 16 115-16 149, 1999.

Louis, J. F.: A parametric model of vertical eddy fluxes in the atmosphere, Boundary Layer Meteorology, 17, 187-202, 1979.

MARTINEK: Study of Greenhouse Gas Emissions form Ships. Report to International Maritime Organization, Norwegian Marine Technology Research Institute (MARTINEK), Trondheim, Norway, 2000.

McConville, A.: Emission standards handbook, EA Coal Research, International Energy Agency, London, UK, 1997.

Mechler, R.: Calculating global methane emissions with the RAINS model, in Internal report of the TAP Project, International Insti- 
tute for Applied Systems Analysis, Laxenburg, Austria, 2003.

MTE: Energy Strategy for Russia for the period up to the year 2020. Ministry of Industry and Energy (MTE) (http://www.mte.gov.ru/ files/103/1354.strategy.pdf), in Russian, Moskva, Russia, 2003.

Murazaki, K. and Hess, P.: How does global warming contribute to ozone changes in the U.S?, J. Geophys. Res., in press, 2005.

Murray, F., McGranahan, G., and Kuylenstierna, J. C. I.: Assessing health effects of air pollution in developing countries, Water, Air, and Soil Pollution, 130, 1799-1804, 2001.

Nakicenovic, N., Alcamo, J., Davis, G., De Vries, B., Fenhann, J., Gaffin, S., Gregory, K., Grübler, A., Jung, T. Y., Kram, T., Lebre La Rovere, E., Michaelis, L., Mori, S., Morita, T., Pepper, W., Pitcher, H., Price, L., Riahi, K., Roehrl, A., Rogner, H. H., Sankovski, A., Schlesinger, M., Priyadarshi Shukla, P., Smith, S., Swart, R., Van Rooijen, S., Victor, N., and Dadi, Z.: Special Report on Emissions Scenarios, Intergovernmental Panel on Climate Change, pp. 599, Cambridge University press, Cambridge, United Kingdom and New York, USA, 2000.

Olivier, J. G. J. and Berdowski, J. C. I.: Global emissions sources and sinks, in: The climate system, edited by: Berdowski, J. J. M., Guicherit, R., Heij, B. J., and Balkema, A. A., Publishers/Swets \& Zeitlinger Publishers, Lisse, The Netherlands, 2001.

Penner, J. E., Atherton, C. S., and Graedel, T. E.: Global emissions and models of photochemically active compounds, in: Global Atmospheric Biospheric Chemistry, edited by: Prinn, R. G., pp. 223-247, Plenum Press, New York, 1994.

Peters, W., Krol, M., Dentener, F. J., and Lelieveld, J.: Identification of an El Nino oscillation signal in a multiyear global simulation of tropospheric ozone, J. Geophys. Res., 106, 19389$10402,2001$.

Pope, V. D., Gallani, M. L., Rowntree, P. R., and Stratton, R. A.: The impact of new physical parametrizations in the Hadley Centre climate model: HadAM3, Clim. Dyn., 16, 123-146, 2000.

Popov, S.: Energy database for the RAINS-Russia model. Internal Paper of the Transboundary Air Pollution Project, International Institute for Applied Systems Analysis, Laxenburg, Austria, 2003.

Prather, M., Ehhalt, D., Dentener, F., Derwent, R., Dlugokencky, E., Holland, E., Isaksen, I., Katima, J., Kirchhoff, V., Matson, P., Midgley, P., and Wang, M.: Atmospheric chemistry and greenhouse gases, Chapter 4, in: Climate Change 2001, The scientific basis: Contribution of working group I to the Third assessment report of the Intergovernmental Panel on Climate, edited by: Houghton, J. T., Ding, Y., Griggs, Y., Noguer, M., v.d. Linden, P. J., Dai, X., Maskell, K., and Johnson, C. A., pp. 881, Cambridge University Press, Cambridge, United Kingdom and New York, NY, US, 2001.

Prather, M., Gauss, M., Berntsen, T. K., Isaksen, I., Sundet, J., Bey, I., Brasseur, G., Dentener, F., Derwent, R., Stevenson, D. S., Grenfell, L., Hauglustaine, L. W., Horowitz, D., Jacob, D., Mickley, L. J., Lawrence, M. G., Kuhlman, R. V., Muller, J.-F., Pitari, G., Rogers, H., Johnson, M., Pyle, J. A., Law, K. S., Weele, M. V., and Wild, O.: Fresh air in the 21 st century, Geophys. Res. Lett, 30 (2), 72-72-4, 2003.

RAINS-Asia: Software Package for Integrated Assessment of Pollution Control Strategies in Southeast Asia, Version 7.5 (http: //www.iiasa.ac.at/rains), International Institute for Applied Systems Analysis, Laxenburg, Austria, 2001.
Ramaswamy, V., Boucher, O., Haigh, J., Hauglustaine, D., Haywood, J., Myhre, G., Nakajima, T., Shi, G. Y., and Solomon, S.: Radiative Forcing of Climate Change, Chapter 6, in: Climate Change 2001, The scientific basis: Contribution of working group I to the Third assessment report of the Intergovernmental Panel on Climate, edited by: Houghton, J. T., Ding, Y., Griggs, Y., Noguer, M., v.d. Linden, P. J., Dai, X., Maskell, K., and Johnson, C. A., pp. 881, Cambridge University Press, Cambridge, United Kingdom and New York, NY, US, 2001.

Rentz, O., Haasis, H.-D., Jattke, A., Russ, P., Wietschel, M., and Amann, M.: Influence of energy supply structure on emission reduction costs, Energy Policy, 19 (6), 641-651, 1994.

Riahi, K. and Roehrl, R. A.: Greenhouse gas emissions in a dynamics-as-usual scenario of economic and energy development, Technological Forecasting \& Social Change, 63 (2-3), 175-205, 2000.

Russell, G., and Lerner, J.: A new finite-differencing scheme for the tracer transport equation, J. Appl. Meteorol., 20, 1483-1498, 1981.

Sanderson, M. G., Collins, W. J., Derwent, R. G., and Johnson, C. E.: Simulation of global hydrogen levels using a Lagrangian three-dimensional model, J. Atmos. Chem., 46, 15-28, 2003.

Shah, J. J., Nagpal, T., and Brandon, C. J.: Urban Air Quality Management Strategy in Asia, A guidebook and a series of city reports, The World Bank, pp. 1-188, Washington, D.C., USA, ISBN-0-8213-4032-8, 1997.

Shindell, D. T., Walter, B. P., and Faluvegi, G.: Impacts of climate change on methane emissions from wetlands, Geophys. Res. Lett., 31 (21), L21202, doi:10.1029/2004GL021009, 2004.

Simmonds, P. G., Derwent, R. G., Manning, A. L., and Spain, G.: Significant Growth in surface ozone at Mace Head, Ireland, 1987-2003, Atmos. Environ., 38, 4769-4778, 2004.

Stevenson, D., Doherty, R., Sanderson, M., Johnson, C., Collins, B., and Derwent, D.: Impacts of climate change and variability on tropospheric ozone and its precursors, Faraday Discuss., 130, 1-17, 2005.

Stevenson, D. S., Johnson, C. E., Highwood, E. J., Gauci, V., Collins, W. J., and Derwent, R. G.: Atmospheric Impact of the 1783-84 Laki eruption: Part I Chemistry modelling, Atmos. Chem. Phys., 3, 487-507, 2003,

SRef-ID: 1680-7324/acp/2003-3-487.

Stevenson, D. S., Johnson, C. E., Collins, W. J., Derwent, R. G., Shine, K. P., and Edwards, J. M.: Evolution of tropospheric ozone radiative forcing, Geophys. Res. Lett, 25, 3819-3822, 1998.

Stevenson, D. S., Doherty, R. M., Sanderson, M. G., Collins, W. J., Johnson, C. E., and Derwent, R. G.: Radiative forcing from aircraft $\mathrm{NO}_{\mathrm{x}}$ emissions: mechanisms and seasonal dependence, J. Geophys. Res., 109, D17307, doi:10.1029/2004JD004759, 2004.

Taylor, K. E., Williamson, D., and Zwiers, F.: The sea surface temperature and sea-ice concentration boundary conditions for AMIP II simulations, in PCMDI Report No. 60 (http:// www-pcmdi.llnl.gov/pcmdi/pubs/ab60.html), Program for Climate Model Diagnosis and Intercomparison, pp. 25, Lawrence Livermore National Laboratory, Livermore, California, USA, 2000.

Tiedtke, M.: A comprehensive mass flux scheme for cumulus parameterization in large-scale models, Mon. Weather Rev., 117, 1779-1800, 1989. 
UN: 1998 Industrial Commodity statistics, United Nations, New York, USA, Series P, no. 41, 2000.

Van der Werf, G. R., Randerson, T. J., Collatz, J., and Giglio, L.: Carbon emissions from fires in tropical and subtropical ecosystems, Global Change Biol., 9, 547-562, 2003.

Van Vuuren, D. P., Cofala, J., Eerens, H., Oostenrijk, R., Heyes, C., Klimont, Z., Den Elzen, M. J. E., and Amann, M.: Exploring the ancillary benefits of the Kyoto Protocol for Air Pollution in Europe, Energy Policy, in print, 2005.

Vingarzan, R.: A review of surface background levels and trends, Atmos Environ., 38, 3431-3442, 2004.

Wang, Y. and Jacob, D. J.: Anthropogenic forcing on the tropospheric ozone and $\mathrm{OH}$ since preindustrial times, J. Geophys. Res., 103, 31 123-31 135, 1998.

Weaver, C. S. and Walsh, M. P.: Air Pollution from Motor Vehicles. Standards and Technologies for Controlling Emissions, The World Bank, Washington D.C., USA, 1996.

West, J. J. and Fiore, A. M.: Management of Tropospheric Ozone by Reducing Methane emissions, Environmental Science and Technology, 39, 4685-4691, 2005.

WHO: Health Aspects of Air Polution with Particulate Matter, Ozone and Nitrogen Dioxide (http://www.euro.who.int/ document/e79097.pdf), pp. 98, EUR/03/5042688, World Health Organisation, Bonn, Germany, 2003.
Wild, O., Prather, M. J., and Akimoto, H.: Indirect long-term global radiative cooling from NOx emissions, Geophys. Res. Lett, 28 (9), 1719-1722, 2001.

World-Bank: Clear Water, Blue Skies. China's Environment in the new century, World Bank, Washington D.C., USA, p. 219, ISBN 0-8213-4044-1,1997.

Wotawa, G., Novelli, P. C., Trainer, M., and Granier, C.: Interannual variability of summertime $\mathrm{CO}$ concentrations in the Northern Hemisphere explained by boreal forest fires in North America and Russia, Geophys. Res. Lett, 28, 4575-4578, 2001.

Yurganov, L. N., Blumenstock, T., Grechko, E. I., Hase, F., Hyer, E. J., Kasischke, E. S., Koike, M., Kondo, Y., Kramer, I., Leung, F.-Y., Mahieu, E., Mellqvist, J., Notholt, J., Novelli, P. C., Rinsland, C. P., Scheel, H. E., Schulz, A., Strandberg, A., Sussmann, R., Tanimoto, H., Velazco, V., Zander, R., and Zhao, Y.: A quantitative assessment of the 1998 carbon monoxide emission anomaly in the Northern Hemisphere based on total column and surface concentration Measurements, J. Geophys. Res., 109 (D15), D15305, doi:10.1029/2004JD004559, 2004. 